\title{
Fotografia no Museu: o projeto de curadoria da coleção Militão Augusto de Azevedo
}

\author{
Vânia Carneiro de Carvalho \\ Solange Ferraz de Lima \\ Museu Paulista/USP
}

objetivo do presente texto é apresentar a coleção de fotografias de Militão Augusto de Azevedo pertencente ao Museu Paulista da Universidade de São Paulo e discutir os procedimentos documentais adotados para o seu tratamento. $O$ valor e o ineditismo da coleção por si só justificariam a sua divulgação neste veículo, entretanto, a análise de certos aspectos metodológicos do trabalho de documentação nos parece relevante. Ela permite demonstrar que a metodologia documental não foi "aplicada" ao seu objeto de interesse como se esta se reduzisse a um simples instrumental, ou seja, um arsenal de medidas técnicas derivadas de um conhecimento universal, abstrato e normativo. As decisões relativas ao tratamento documental foram, ao contrário, orientadas por um conceito de curadoria que fomenta explorações científico-culturais especificas.

A curadoria

Tradicionalmente, a atividade de curadoria em museus está associada a sentidos administrativos e técnicos. O curador é o responsável pela guarda do acervo institucional; dele depende a aplicação de formas de controle patrimonial, de tratamento físico e documental das coleções e arquivos. Como decorrência deste enfoque, o curador é entendido como um profissional que detém um conhecimento técnico especializado sobre o segmento documental por ele tratado.

Modernamente, a função de curadoria refere-se também à organização de exposições. Neste caso, o curador, do qual também se espera 
1. Exceçào deve set feita às coleçoes arqueológicas tradicionalmente coletaclas por pesquisadores ligados a procedimentos sistemáticos de identificaçào e organizaça das peças en relaçào ao sîtio arqueológico. (Fürst, 1989) o domínio especializado do universo documental contemplado pela exposição, tem a tarefa de definir o conceito da mostra e fazer a intermediação entre as diferentes áreas de produção - patrocínio, pesquisa, levantamento e documentação institucional dos objetos selecionados para a exibição, projeto museográfico e tudo o que ele implica como, por exemplo, projeto de iluminação, projeto arquitetônico (criação do mobiliário expositivo, objetos cenográficos etc.l, designer gráfico, sonoplastia, cenografia, montagem etc. (Kavanagh, 1990:127; Sola 1992:101\}.

Quando entendida como atividade de natureza organizacional, a curadoria sofre as conseqüências de uma compartimentação do conhecimento, que a torna uma função prisioneira do objeto de suas atenções o acervo. 0 domínio técnico gerado a partir das necessidades de documentação (datação, identificação de autoria, técnica, formas de circulação etc.) ou da obrigação de preservar a integridade física do objeto tem se constituído de forma desvinculada dos usos e sentidos que o documento em questão assumiu na vida social'. O objeto de acervo é tratado como uma peça isolada, como se o seu valor fosse algo intrínseco à materialidade do objeto.

A ausência de procedimentos próprios da pesquisa, ou seja, de critérios teórico-metodológicos derivados da área de conhecimento à qual se pretende vincular o acervo museológico tem sido a responsável por distorções no controle documental, especialmente em um dos momentos cruciais de constituição da base empírica de qualquer produção de natureza científica, isto é, a coleta de acervo.

Fora destes parâmetros, e sem o entendimento da lógica social que regeu a constituição dos diversos núcleos documentais, o conhecimento que é produzido na "tarefa" de seleção e nomeação dos objetos de uma coleção tende a ser percebido como um conjunto de indícios diretamente apropriado do documento e não algo construído pelo curador (Gathercole, 1989:74; Meneses, 1994: 191. Quando o conhecimento mantém-se reduzido ao objeto museológico assim fetichizado, resta ao curador apenas uma sucessão de tarefas operacionais a serem cumpridas.

Nas áreas de exposição, o uso da pesquisa como simples apêndice resulta em um esvaziamento daquilo que se pretende "comunicar". Fatos do chamado "contexło histórico", quando a este se lança mão, carregam marcas de cunho biográfico (no caso de obras de arte), celebrativo (objetos históricos de grandes personagens políticos, por exemplo) ou ainda pitoresco (fatos históricos aleatoriamente citados como curiosidades). O contexto aqui funciona como uma paisagem de fundo, como "aparência visual, isto é, recorte empírico que, como tal, precisaria ser explicado, pois não é auto-significante." (Meneses, 1994:30).

Atuando no gerenciamento de reservas técnicas, o procedimento da curadoria pode ou não viabilizar a pesquisa, já que a preservação do documento significa não apenas a conservação da integridade física do objeto, mas o registro da rede de informações à qual ele pertenceu até o momento de sua musealização. No caso de um museu de história, expor documentos sem a orientação que a disciplina oferece perpetua a sua ação como legitimador de noções oficiais (geralmente de caráter celebrativo), enquanto que, para a 
universidade, ele permanece em uma posição periférica, funcionando como depósito de objetos ou espaço disponivel para eventos.

Mesmo quando convencido da necessidade de mudanças, o curador de museus de história arca com as conseqüências de práticas herdadas do século passado. Ele tem de lidar com catálogos com parcas informações, quase nenhuma sobre contexto e uso do objeto, todas produzidas anonimamente e muitas acrescentadas posteriormente sem distinção dos dados originais (comprometendo as informações do coletor). Tem também de organizar coleções formadas aleatoriamente ou segundo critérios pouco consistentes para a exploração científica _ objetos selecionados para legitimar o prestígio político ou econômico de figuras com destaque na sociedade, objetos selecionados pelo seu valor estético, objetos considerados "lixo" pela família doadora, ou seja, aquilo que a própria família já não consegue identificar ou encaixar na lógica de sua coleção pessoal etc.. O curador convive, enfim, com um número significativo de objetos fora do catálogo, ou sem controle do coletor laté mesmo sem data de entrada e procedêncial, além de restaurações sem nenhuma documentação, e que por vezes resultaram na inutilização da peça para a pesquisa (Fürst, 1989). A herança de procedimentos de catalogação e exposição com base em critérios extra-científicos, somada ao desprestígio das funçōes de curadoria dentro da universidade são os produtos de uma prática recorrente na área de ciências humanas que sempre utilizou de forma secundária os documentos provenientes da cultura material.

Para além das medidas de saneamento com relação à situação existente, parece que somente a pesquisa como orientadora de todas as atividades de curadoria poderá reverter este quadro. Por isso, desde 1989, o Museu Paulista concentra esforços no sentido de colocar em prática um conceito de curadoria que rearticule a produção do conhecimento às atividades de cunho organizacional, museográfico e ao domínio técnico especializado do documento (Meneses, 1990). Ao contrário da concepção do museu como vitrine da riqueza material da sociedade e de si mesmo, pretende-se colocar à disposição do usuário um "fesouro" informacional, que se constitui através do desenvolvimento coerente de curadorias que vinculam políticas de aquisição e tratamento de acervo, formação de biblioteca, produções pedagógica, cultural e acadêmica. Não se trata, portanto, de transformar o museu da elite política e econômica paulista em um museu demagogicamente popular. O caráter democrático do museu tem como base não a legitimação dos valores deste ou daquele segmento social, mas a construção (e desconstrução) de processos históricos pertinentes ao conjunto da sociedade. As informações não são oferecidas para o consumo de uma "grife" de museu, ou como erudição pela erudição, mas sim para servirem de ferramenta na capacitação do individuo no enfrentamento de sua própria trajetória histórica.

Na perspectiva de estabelecer uma base documental sólida, um dos objetivos da curadoria tem sido implementar uma política de aquisição de séries documentais orgânicas (documentos gerados a partir de uma atividade) ou funcionais lobjetos de escritório, de toucador, de iluminação, de uso para alimentação, de uso cerimonial, de lazer, etc.), cujas tipologias são selecionadas 
2. A função simbólica com relaçào aos objetos considerados históricos está na origem da formação do Museu Paulista como memorial da independência, da nação e da paulistanidade. Sobre o tema ver Brefe, Ana Cláudia. Um lugar de memória para a Naçào. O Museu Paulista reinventado por Afonso d'Escragnole Taunay (1917-1945). Campinas, 1999. Tese (Doutorado), Universidade Estadual de Campinas (ms.).

3. Em outubro de 1990 foi montado um dossiê sobre a coleçào, entào em posse da bisneta do fotógrafo, Raquel de Azevedo Salles, e deuse início à busca de patrocínio. Em janeiro de 1996. após cadastramento do projeto no Programa Nacional de Apoio à Cultura, do Ministério do Cultura, a Fundaçào Roberto Marinho e a Rede Globo decidiram patrocinar nào apenas a aquisição da coleçào mas o projeto de curadoria elaborado pelo Museu aqui apresentado. a partir de critérios que regem o desenvolvimento das linhas de pesquisa existentes.

$\bigcirc$ interesse por objetos de uso simbólico², matéria-prima indispensável nos problemas relativos à história do imaginário, e a existência de um núcleo inicial relevante como a pinacoteca do Museu, que reúne retratos e paisagens urbanas, muitas com inspiração fotográfica, foram razões que se somaram ao interesse pela coleção de fotografias de Militão Augusto de Azevedo: um conjunto de mais de 12.000 fotografias, produzidas entre 1862 e 1887, e procedentes de uma única fonte produtora _ o estúdio Carneiro \& Gaspar, adquirido pelo então sócio Militão e, posteriormente denominado Photographia Americana

A coleção

fotógrafo oitocentista Militão Augusto de Azevedo é conhecido pelos estudiosos da

Cidade de São Paulo em virtude dos registros fotográficos urbanos que realizou, dando origem ao Álbum Comparativo da Cidade de São Paulo, 1862-1887/cf. Toledo \& Kossoy, 1981; Lemos, 1982). A sua atividade como retratista, no entanto, foi pouco divulgada para além do circuito da história da fotografia no Brasil Kossoy, 1978; Grangeiro, 1993; Laurito, 1982) e a documentação a ela relacionada permaneceu prałicamente inédita, em posse da família até 1996, quando passou a integrar os acervos do Museu Paulista da USP graças ao patrocínio da Fundação Roberto Marinho e da Rede Globo de Televisão. ${ }^{3}$

Militão Augusto de Azevedo nasceu no Rio de Janeiro em 1837. Aos 25 anos, integrando a Companhia Dramática Nacional, veio para São Paulo e aqui se estabeleceu, trabalhando como retratista na filial do atelíl carioca Carneiro \& Gaspar, aberta em São Paulo, no ano de 1862, por Gaspar António da Silva Guimarães. Em 1875, Militão, já sócio do estabelecimento, adquire o estúdio e passa a denominálo Photographia Americana. Nos seus 20 anos de atuação, o ateliê recebeu clientes ilustres e anônimos: o Imperador D.Pedro II, a Imperatriz Teresa Cristina, o jurista e político Rui Brabosa, o poeta Castro Alves, os abolicionistas Luís Gama e Joaquim Nabuco, Antônio de Lacerda Franco, intelectuais como José Maria Lisboa, Eduardo da Silva Prado, Frei Germano de Annecy, primeiro astrônomo de São Paulo, o pintor Rodolfo Amoedo, artistas de companhias teatrais que na cidade faziam suas temporadas, funcionários públicos e liberais como médicos, advogados, engenheiros, trabalhadores anônimos, escravos e alforriados, pessoas com deformações físicas, cadáveres, inúmeras crianças, casais, mães com bebês etc. Militão identifica também categorias profissionais nas figuras do primeiro barbeiro, do professor de piano, da engomadeira, da prostituta, enfim, homens e mulheres que formam um imenso painel de tipos humanos no século XIX.

Ao fechar seu estúdio, em 1885, Militão se desfaz do laboratório, leiloando máquinas, materiais e apetrechos fotográficos, mas mantém a documentação textual e iconográfica. Esta documentação chega à contemporaneidade mantida pela família de seu primogênito, Luiz Gonzaga de 
Azevedo, com quem Militão manteve laços estreitos até seu falecimento, em 1905.

A maior parte da documentação que compõe a Coleção Militão Augusto de Azevedo é formada pelo que se acredita serem os livros de controle e mostruário dos dois estúdios, e que trazem mais de 12.000 retratos, produzidos originalmente no formato carte-de-visite e cabinet-portrait. Os retratos encontramse reunidos em seis encadernações em couro, com datas gravadas nas lombadas, colados inteiros ou recortados de modo a identificar apenas o rosto do cliente. Uma numeração manuscrita que legenda cada imagem servia provavelmente como número de localização das chapas de vidro que os ateliês costumavam guardar para atender à solicitação de novas cópias.

Fazem ainda parte da coleção 48 negativos de vidro emulsionados com colódio que constituem as matrizes de alguns dos retratos constantes nos livros de controle, fotografias estereoscópicas, fotografias avulsas em albúmen, entre elas imagens da construção da São Paulo Railway (ferrovia Santos-Jundiai), os álbuns da cidade de Santos e São Paulo em 18624, além de quatro documentos manuscritos: o livro indice das Photographias de Antigos Paulistas, que identifica algumas centenas de retratados; um livro-copiador de cartas enviadas por Militão a fornecedores, clientes e amigos; um diário de viagens feitas à Europa e América do Norte, e, por fim, a tradução inacabada do livro Le Paysage Artistique en Photographie de Frederic Dillaye sobre técnica folográfica.

Uma das peculiaridades desta coleção, o que a torna mais interessante, é a reunião de documentos que fornecem pistas sobre um circuito de produção, consumo, reciclagem e descarte dos produtos fotográficos. O controle da produção e a relação com a clientela são indicados nos livros que trazem, até mesmo, comentários manuscritos sobre o cliente (se pagou ou não, se gostou do retrato etc.) e no Indice das Photographias de Antigos Paulistas. $O$ controle de qualidade das imagens fotográficas, por sua vez, pode ser inferido a partir dos testes com viragens e tipos de papéis, perceptíveis nas diversas cópias de uma mesma imagem, como no caso de parte das fotografias avulsas relativas à ferrovia Santos-Jundiaí.

As vicissitudes da atividade de um retratista no século XIX estão registradas no livro-copiador de cartas com riqueza de detalhes quanto às relações com fornecedores, estratégias e dificuldades de comercialização de vistas urbanas, o que permite acompanhar a ascensão e declínio do ateliê Photographia Americana. Ainda com base no livro-copiador, é possivel datar o uso de materiais e apetrechos fotográficos, distingüindo-se, por exemplo, a introdução de novos métodos e materiais no Brasil com relação à Europa.

O diário de viagens já permite abordagem distinta: revela o olhar de alguém sintonizado com sua época, que comenta acontecimentos políticos e sociais, além de trazer à luz informações sobre o modo de vida de uma classe que podemos considerar equivalente ao que usamos denominar hoje como classe média - formada por profissionais liberais, funcionários públicos, comerciantes. Neste caso, é particularmente interessante conhecer, por exemplo, quais os rituais de um encontro com amigos num jantar informal, preços e detalhes dos
4. A Biblioteca do Museu Paulista possui dois exemplares (não identicos) do Álbum Comparativo de Vistas da Cidade de sào Pallo, 1862 e 1887. 
5. Mendes, Ricardo. Literatura Técnica (1840-1940): Enciclopédias, manuais, periódi cos. São Paulo: Centro Cultural São Paulo/ SMC-Prefeitura Municipal, 1991/1992. (ms).

6. Estatueta representando grupo de cupidos (petit amours) em metal branco sobre base de alabastro de autoria de Isidore Romaim Boitel. transportes utilizados, enfim, ações cotidianas cujo registro dificilmente tem lugar em documentos mais convencionais.

Por fim, a tradução manuscrita do livro de Frederic Dillaye, projeto aparentemente inconcluso de Militão, nos dá a medida da atualização possível naquela época. Dillaye era fotógrafo-retratista em Paris e atuante na pesquisa e divulgação da estética fotográfica. Outras obras dele foram localizadas, datadas no final do século, em bibliotecas públicas de São Paulo5.

Com a coleção Militão foi adquirida também a de seu fillho Luiz Gonzaga de Azevedo, fotógrafo amador que produziu entre 1905 e 1924 mais de duas centenas de fotografias organizadas em álbuns de família, além de negativos em vidro e flexiveis. $O$ conjunto se completa com uma agenda-diário onde foram registrados pelo próprio Luiz Gonzaga acontecimentos familiares, um caderno com anotações e recortes de jornais sobre a vida profissional do titular e nove livros-copiadores de cartas, estes últimos doados posteriormente.

Assim como na Coleção Militão, uma riqueza de informações abarcando diferentes setores da vida social cotidiana pode ser aqui explorada. Luiz Gonzaga de Azevedo nasceu no Rio de Janeiro em 1862 e faleceu em São Paulo em 1928. Estudou economia e finanças, exercendo as funções de diretor do Tesouro do Estado e do Banco de São Paulo. Sua atividade profissional rendeu-the relações com membros da elite intelectual paulistana. Sua casa era freqüentada por pessoas como Ramos de Azevedo, arquiteto que projetou sua residência, e laços de parentesco se formaram entre os Gonzaga e a família de Herman von Ihering, naturalista que dirigiu o Museu Paulista na primeira década deste século.

Finalmente, confrontando as duas coleções é possivel acompanhar a trajetória de ascensão de uma família numa época caracterizada pela mobilidade social. Militão dispunha de poucos recursos e contava, basicamente, com os ganhos de sua atividade como fotógrafo, tendo lutado, como transparece em suas correspondências, com dificuldades para manter seu padrão de vida. No caso da família de seu primogênito, Luiz Gonzaga, a situação já é outra. As fotografias, sua agenda-diário e as cartas revelam um modo de vida bem mais confortável e sofisticado: viagens à praia, saraus musicais, para os quais se dispunha inclusive de uma sala de música com piano, festas e jantares cujos registros denotam fartura.

Posteriormente à doação patrocinada, a família Azevedo, representada por Raquel de Azevedo Salles, doou uma cadeira e uma escultura ${ }^{\dagger}$ que pertenceram ao est dio Photographia Americana. No decorrer do processo de tratamento da coleção, foi feito contato com a Sra. Heloísa Azevedo, também bisneta de Militão, residente em Curitiba, de quem o Museu Paulista adquiriu uma lanterna mágica, de procedência inglesa, que também pertenceu a Militão e que, segundo depoimentos, foi, por muitos anos, objeto de entretenimento nas reuniões familiares.

\section{processamento documental}

\section{Estratégias}

As estratégias adotadas para o processamento da coleção foram no sentido de compatibilizar verbas e cronograma pré-estabelecidos pela Fundação 
Roberto Marinho com as necessidades de pesquisa e documentação. Uma das prioridades foi tornar toda a documentação disponível para o público no espaço de apenas um ano. A otimização do tempo de catalogação das imagens dependeu, fundamentalmente, do sistema informatizado adotado e do número de profissionais envolvidos.

É importante salientar que o cumprimento do cronograma de um ano para a catalogação de 13.120 imagens só foi possivel por já dispormos de uma ficha cadastral definida para o acervo iconográfico do Museu e de um programa de informatização especialmente desenvolvido para este fim. Assim, para o cadastramento das coleções Militão e Luiz Gonzaga, partiu-se de uma estrutura existente - ficha e manual de preenchimento, vocabulário controlado já esboçado e programa de informatização desenvolvido?.

Dada a quantidade de documentos das duas coleções, que aumentou em $76 \%$ o acervo iconográfico sob a guarda do Serviço de Documentação Textual e Iconografia do Museu (ca. 17.000 para 30.000 unidades), optou-se pela criação de uma módulo especial, cuja estrutura e campos de preenchimento derivaram da ficha iconográfica existente. Essa estratégia permitiu a inserção, de uma só vez, dos dados comuns à totalidade das imagens (histórico da coleção, doador, avaliação, agente produtor, período da produção etc.). Desta forma, a catalogação unitária pode se restringir aos campos que diziam respeito às características individualizadoras das imagens - legendas, dados técnicos (como dimensōes, técnicas), estado de conservação e descrição do conteúdo.

\section{A ficha catalográfica}

A ficha catalográfica foi elaborada visando reunir quatro categorias de informações (ver anexo l): dados de identificação do documento e de sua produção; dados técnicos relativos ao suporte; dados administrativos referentes à patrimoniação do documento junto ao Museu Paulista e à Universidade de São Paulo; e, por fim, dados relativos à produção e difusão do conhecimento envolvendo o documento em questão.

Para comportar essas categorias de informações, o programa desenvolvido contou com três tipos de campos:

a) campos em que é possivel a definição prévia de todos os termos que serão utilizados como, por exemplo, o campo dados técnicos. Por se tratar de um coleção única, todas as técnicas fotográficas presentes puderam ser elencadas previamente e, assim, ao invés de digitar a cada imagem a palavra que indica a técnica utilizada, seleciona-se de uma listagem acessada por barra de rolagem o item correspondente. Este tipo de campo ocupa menos memória, agiliza a inserção de dados além de minimizar a ocorrência de erros de digitação;

b) campos com número de caracteres pré-definidos e que exigem, portanto, uma estimativa quanto a seu uso (tamanho das palavras). Por exemplo: para o campo título/legenda o número de caracteres máximo é 256, o que significa que, a partir de simulaçōes prévias, concluiu-se que seria improvável haver na coleção uma legenda acima deste número de caracteres;
7. O sistema documental informatizado do Museu foi desenvolvido pelo analista de sistemas Luciano Antônio Beraldo. responsável também pelo seu gerenciamento e aperfeiçoamento. 
8. Os arquivos parale los não estào ainda disponîveis para consulta.

9. Felizmente, desde então o Museu Paulista vem sendo beneficiado com equipamentos pela FAPESP, pela própria Universidade de São Paulo e, no caso das coleções aqui abordadas, pela Fundaçào Roberto Marinho que doou dois microcomputadores Pentium, um scanner de cromos e negativos, mesas para acomodação dos equipamentos e material de consumo para embalagem dos originais. Além disso, arcou com a remuneraçào temporária de três historiadotes, um restaurador e três estagiários. (ver Anexo III) c) campos abertos, que não contam com limites definidos de caracteres e que foram adotados para a inserção de dados de difícil previsão como o campo histórico, destinado a informações de contextualização da imagem catalogada como biografias, histórico de logradouros, além da própria história de formação da coleção e de como chegou ao Museu. Este tipo de campo é o que ocupa mais memória.

Visualmente, a ficha cadastral encontra-se organizada em quatro telas e conta com um menu de opções e acesso aos arquivos principal e paralelos. No caso dos retratos, duas imagéns _ a fotografia catalogada e a página do álbum em que esta se encontra _ abrem a primeira tela de cada ficha do catálogo (ver Anexo l).

Além do banco principal de dados, o programa permitiu a criação de arquivos paralelos (ou de apoio) que reúnem informações que situam a produção referenciada pelo banco _ biografias dos autores das imagens, histórico dos agentes produtores (no caso os ateliês), glossário referente às técnicas fotográficas do século XIX etc. _ informações que, se repetidas à exaustão em cada ficha do arquivo principal, acabariam por torná-lo inutilmente longo e tedioso, dificultando a sua manipulação ${ }^{8}$. $\bigcirc$ programa conta ainda com relatúrios previamente construldos para impress "O de listagens resumidas do acervo catalogado.

$A$ rede

O Serviço de Documentação, onde pode ser consultado o banco de dados das coleções Militão e Luiz Gonzaga, possui cinco microcomputadores do tipo Pentium, os quais estão em rede compartilhada (Windows NT). Esta rede, por sua vez, está conectada a um servidor NT, gerenciado pelo analista de sistemas do museu. Neste computador, com maior capacidade de armazenagem (8 Gigabytes com capacidade de ampliação), fica o catálogo das duas coleções. Um segundo servidor de igual capacidade é utilizado para a cópia de segurança do material cadastrado. O banco de dados, bem como todo o sistema de cadastramento da instituição foi desenvolvido em Foxpro 2.6.

Vários foram os fatores que concorreram para a escolha deste programa. Em 1991, quando se iniciaram os trabalhos de recadastramento do acervo da instituição e quando foi possivel preencher a única vaga disponivel no museu para um analista de sistema, o Centro de Computação Eletrônica da USP tinha pouco conhecimento sobre a organização de bancos de imagem na área de ciências humanas. Sem assessoria da universidade e contando com apenas um microcomputador na área científica, o analista traçou uma estratégia de informatização do museu de modo a oferecer autonomia a cada unidade do sistema projetado permitindo que este pudesse ser instalado, pelo menos em parte, caso não fosse possivel contar com investimentos pesados em equipamentos ${ }^{9}$.

O programa foxpro é de baixíssimo custo se comparado aos programas de banco de dados científicos e possui distribuição livre, ou seja, não há exigência de licença para cada computador integrado a uma rede. Os programas cientfficos (por exemplo, o Oracle) oferecem maiores recursos de programação e são mais ágeis para a consulta. Entretanto, além de implicar na elevação de custos, a sua manipulação exige especialização, o que 
comprometeria o tempo e os poucos recursos humanos envolvidos no programa de cadastramento da área científica da instituição. Cabe lembrar que um catálogo, uma vez produzido, sempre poderá ser convertido para outro programa, conforme assim o exigir as circunstâncias e as oportunidades de aperfeiçoamento do sistema. Finalmente, a opção pela rede compartilhada ao invés de uma configuração de rede centralizada fez de cada microcomputador cliente e servidor ao mesmo tempo, segundo uma distribuição dos bancos de dados e programas da instituição, evitando-se, assim, o colapso do sistema no caso da quebra de uma de suas máquinas.

Outra vantagem deste programa é a possibilidade de associar imagens ao banco de dados, o que permitiu o encaminhamento de catálogos digitais capazes de mediar, com eficácia, a consulta aos originais.

\section{A digiłalização das imagens}

Diante das novas possibilidades de captação digital de imagens, garantindo assim o registro documental com o máximo de economia de espaço e de custos na manutenção do acervo de segunda geração, certamente se pensou, de imediato, em adotar essa estratégia de reprodução. Esse era, inclusive, o desejo da coordenação de projetos da Fundação Roberto Marinho. No entanto, a pouca oferta, na época, de equipamentos desta natureza no mercado nacional bem como a necessidade de compatibilizar diversos custos dentro de uma verba pré-determinada mudou as expectativas.

A primeira possibilidade aventada, as câmeras de captação digital, não dispunham, ainda, de lentes e filtros capazes de garantir registros de qualidade semelhante aos obtidos com as máquinas fotográficas. Os modelos de uso doméstico de forma alguma se adequavam às necessidades de documentação de acervos museológicos, especialmente no caso de imagens muito reduzidas, como era o caso da coleção Militão. Segundo informações levantadas junto a fotógrafos profissionais, os equipamentos para captação digital capazes de resultados de qualidade semelhante ou mesmo superior à captação por meios químicos _ dispositivos acopláveis a máquinas para negativos em formatos $4 \times 5^{\prime}$ e $120 \mathrm{~mm}$ _ eram ainda pouco testados em arquivos históricos e de custo exorbitante para a dimensão e objetivos do projeto.

Os scanners, por sua vez, já testados em uma multiplicidade de aplicações há certo tempo, apresentavam grandes vantagens com relação às câmeras digitais no que se refere à resolução das reproduções e aos custos. Infelizmente, sua utilização na captação digital de imagens fotográficas do século XIX é desaconselhável pois a intensidade da luz e do calor, semelhantes aos emitidos pelas máquinas copiadoras, causam esmaecimento e ondulações das fotografias em albúmen ${ }^{10}$.

Em visita lécnica ao Serviço de Documentação do museu, conservadores do Centro de Conservação e Preservação de Fotografias/Funarte recomendaram, dada a raridade das fotografias e dos negativos em vidro das coleções Militão e Luiz Azevedo, a reprodução fotográfica em filme p\&b (negativo de segunda geraçãol, que permitiria posterior digitalização e estaria disponivel para ampliações destinadas a publicações e exposições.
10. Já existem no mercado internacional modelos de scanners que digitalizam a partir de processos que prescindem de iluminação intensa; nào houve, no entanto, tempo hábil para um levantamento mais extenso e muito menos para o encaminhamento do processo de impottação. 
11. Os trabalhos de reproduçào ficaram a cargo de Sérgio Burgi.

12. A equipe de pesquisa e documentação contou com tres historiadoras com experiencia na área de organização e catalogaçào documental e duas estagiárias graduandas de historia (ver Anexo III).

Assim, decidiu-se que seria mais interessante e adequado ao tipo de acervo iconográfico do Museu a digitalização de negativos ou diapositivos. Sujeitas a um esmaecimento progressivo, que, no limite, implica no desaparecimento da imagem, as fotografias em albúmen reproduzidas pelo processo fotográfico teriam cópias de segunda geração de alta fidelidade. Além disso, com a digitalização direta do filme evitar-se-ia a duplicação do acervo com ampliações em papel, que exigem espaço e embalagens, ao mesmo tempo que se garantiria um nivel de resolução de qualidade, tanto para a referência catalográfica no módulo de consulta, como para a utilização em CD-ROMs, exposiçōes e impressos (cartões postais, catálogos, cartazes). Com um scanner para negativos e diapositivos, a instifuição otimizaria o registro e divulgação de seus acervos iconográficos.

No caso das coleções Militão e Luiz Gonzaga, todas as imagens foram reproduzidas em diapositivos $35 \mathrm{~mm}$ e as paisagens, além da reprodução em diapositivo, receberam uma segunda, em formato $6 \times 6 \mathrm{~cm}, p \& b$. A opção pelo diapositivo, que num primeiro momento parece discutivel se pensarmos na instabilidade do flexível colorido com relação ao p\&b, e pelo formato $35 \mathrm{~mm}$ ao invés dos formatos maiores _ $4 \times 5 \mathrm{~cm}$ e $6 \times 6 \mathrm{~cm}$ - , recaiu sobre dois fatores básicos levantados pelo fotógrafo responsável pelas reproduções ${ }^{11}$.

- primeiro está relacionado com o reconhecimento hoje da importância dos atributos plásticos da imagem na sua compreensão como documento histórico. Sendo assim, era imprescindivel preservar, através da reprodução, não apenas o "conteúdo" de cada imagem, mas a diversidade cromática existente na coleção. Para historiadores, conservadores e fotógrafos interessados na trajetória técnica da fotografia e nas condiçōes de preservaçōo fotográfica, as inúmeras tonalidades das fotografias de Militão, resultado de viragens, pigmentos aplicados ao papel albuminado e ação da luz, fornecem importantes pistas para pesquisas nesse campo. Em registros p\&b, a disponibilidade dessas informações só se daria com a consulta aos originais, contrariando o objetivo primeiro da catalogação acompanhada de imagem digital que é justamente preservar ao máximo a coleção do manuseio constante.

- segundo fator de decisão pelo diapositivo se refere ao formato $35 \mathrm{~mm}$, que consideramos apropriado para uma coleção onde $90 \%$ das fotografias coladas nos álbuns têm dimensões pequenas (média de $4 \times 3 \mathrm{~cm}$ ), fazendo com que a proporção entre formato e dimensão do original fotográfico seja na escala natural.

Equipe e execução

A catalogação informatizada foi precedida por uma etapa de familiarização da equipe ${ }^{12} \mathrm{com}$ a coleção, que envolveu leituras relativas à fotografia no século XIX e à vida e produção de Militão Augusto de Azevedo. Nesta etapa tiveram lugar também as discussões preliminares em torno de questões operacionais referentes ao modo de numeração das imagens, normalização dos termos a serem adotados para descrever o estado de conservação e preparação dos dados a serem inseridos simultaneamente nas fichas catalográficas. 
É importante salientar que, em projelos desta natureza, é impossivel prever e ter, portanto, soluções prévias para aquelas questões que só aparecem no decorrer dos trabalhos, especialmente aquelas relativas ao desempenho dos descritores. O entrosamento da equipe, neste caso, é fundamental, pois o sucesso do projeto depende de decisões tomadas em conjunto e que devem levar em conta a experiência de cada um.

Quando se trata de cadastramento de documentação maciça, não se deve esquecer que somente a inserção sistematizada e padronizada das informações garante a sua recuperação no futuro. Portanto, cada decisão tomada quanto a um novo termo para descrição do estado de conservação ou para o conteúdo da imagem precisava, necessariamente, ser discutida por toda a equipe e a alteração registrada seja no manual de preenchimento da ficha, seja no vocabulário controlado de descritores.

Buscando-se o máximo de uniformidade na descrição do conteúdo das imagens, a catalogação dos retratos e paisagens de Militão ficou a cargo de duas historiadoras, que permaneceram nesta atividade durante todo o processo de trabalho' ${ }^{13}$. A terceira historiadora dedicou-se inicialmente à coleta de depoimentos junto aos familiares de Luiz Gonzaga e Militão Augusto de Azevedo, o que possibilitou a identificação dos retratados nos álbuns da família Azevedo. Paralelamente foram pesquisadas as biografias relativas aos retratados identificados por Militão em seu Livro-índice ${ }^{14}$.

As estagiárias ${ }^{15}$ colaboraram em todas as atividades da equipe, notadamente no levantamento de informaçōes relativas aos logradouros fotografados e na localização de propagandas e informações gerais sobre a atividade fotográfica em jornais e almanaques. Tiveram também a oportunidade de participar das etapas preliminares de higienização das fotografias e negativos da coleção. Em reuniões semanais ou quinzenais realizadas com toda a equipe eram avaliadas as atividades em curso e definidas as estratégias para as etapas seguintes.

Nessa primeira etapa de tratamento documental, a ficha catalográfica foi o principal instrumento para onde convergiram todas as informações que seriam posteriormente mobilizadas na elaboração de produtos culturais. Concebida não só para servir como escopo de instrumentos de pesquisa lguias, catálogos etc.), a ficha catalográfica, pelas categorias de informações que reúne dados relativos à trajetória da coleção (como se formou, como chegou ao museu), ao conteúdo específico do documento visual (biografias dos retratados, histórico dos logradouros), e à sua difusão (usos em publicações e exposições) bem como pelos arquivos paralelos que dela derivam, exige mais que um conhecimento puramente técnico. Ela cobra uma constante atualização e acaba por espelhar o processo de pesquisa no quadro institucional que a gerou. A pesquisa necessária para o preenchimento desses campos foi delerminante para definir o perfil da equipe montada para o desenvolvimento dos trabalhos.

O vocabulário controlado

A produção maciça de peças visuais, o reconhecimento da natureza específica da imagem visual e o decorrente interesse por parte de instituições de
13. A catalogação da coleção Militão foi realizada por Cláudia Moi e Regina Mara Teles.

14. Os depoimentos, a catalogação da coleçào Luiz Gonzaga, a pesquisa biográfica e a digitalização das imagens foram realizados por Renata Barbosa Garbellini.

15. Juliana Firmo dos Santos, Montserrat Moreno e Anna Luisa Sarti. 
16. Isto nào significa que a documentação textual, em determinados casos, não possa ou não deva ser tratada unitariamente, ou seja, na formá catalográfica, ou, ao contrário, que séries iconográficas ( $p$ ex. o caso das missies fotográficas) nào possam ser tratadas como conjuntos. A decisão pelo tratamento unitário depende da heterogeneidade e quantidade de material a ser catalogado, bem como freqüência de consulta e quantidade de informaçōes específicas (p.ex. nomes próprios no caso de documentaçôes textuais) nào contempladas pelo tratamento de conjunto. guarda e de pesquisa em colecionar peças seriadas fomentaram questões basilares em torno da formulação e uso de sistemas de recuperação de informações visuais em bases informatizadas. Formar, gerenciar e ampliar coleções de documentos implica em, necessariamente, desenvolver sistemas classificatórios que permitam sua visualização enquanto totalidade, definindo assim um perfil, sem a perda de identificação das partes. Os guias, catálogos, inventários, thesauri, vocabulários controlados exprimem arranjos artificiais de suportes materiais de informação. Para atender com sucesso às necessidades para as quais foram desenvolvidos, esses instrumentos dependem de critérios que garantam a manutenção de sua estrutura e a sistemática de funcionamento. Esses critérios, por sua vez, encerram visões determinadas do público que se deseja atingir e da própria coleção.

Ao longo dos últimos cinco anos, no encaminhamento de experiências envolvendo a reorganização física e documental do acervo do Serviço de Documentação Textual e Iconografia do Museu Paulista com vistas à informatização, deparamo-nos com questões que exigiram o estabelecimento mínimo de critérios para a elaboração de um sistema de busca. A proposta de registro específico e único, a opção por não descrever textualmente a imagem e sim através de palavras-chave e a própria abrangência do vocabulário decorrente foram alguns deles.

A adoção de uma ficha específica e unitária para o suporte iconográfico foi o primeiro passo e marca a especificidade do documento visual com relação ao livro e ao documento textual. $\bigcirc$ tratamento arquivístico, que agrupa a documentação em séries, no interior de um quadro de arranjo que espelha a vida do órgão gerador desses documentos, apesar de fundamental para a integridade das informações, não parece suficiente para responder às necessidades de busca do documento iconográfico. O tratamento biblioteconômico, por sua vez, ao privilegiar autoria e título mostra-se até certo ponto ineficaz para o tratamento de imagens produzidas e consumidas em massa, muitas vezes anonimamente, como é o caso das fotografias que não são de exceção (como as realizadas por fotógrafos consagrados pelo mercado de artes) e algumas tipologias de impressos iconográficos como cartazes, figurinhas e propagandas. Visando contornar este problema, um vocabulário apropriado ao formato de documentação de acervos iconográficos em bibliotecas foi desenvolvido pela Library of Congress (Washington/EUA) - Thesauri for Graphic Materials. A Biblioteca Nacional (R), por sua vez, adaptou para seus acervos os termos descritivos do TGM, complementando o seu Manual para Catalogação de Documentos Fotográficos (1992).

A aplicação de ficha unitária representa o reconhecimento do documento visual como portador de informações que transcendem, pelo menos com mais freqüência, aquelas geradas pelo seu produtor ou proprietário final. Para citar um exemplo, o cartão postal ilustrado com uma paisagem urbana, muitas vezes de autoria desconhecida, interessa obviamente pela mensagem que traz em seu verso, acrescentando dados sobre a trajetória de vida do titular da coleção, mas ele pode informar também sobre a cidade que retrata, fornecendo informações de caráter empírico relativas à morfologia urbana, por exemplo ${ }^{16}$. 
O estabelecimento de uma ficha específica implica em criar portas de acesso às informações sobre cada suporte visual. Nesse ponto esbarramos com outra questão que mobiliza ainda hoje o debate na área de tratamento documental e que diz respeito à abrangência desejeavel de um sistema classificatório. Ele deve ambicionar o universalidade, a exemplo do sistema decimal utilizado ainda hoje pelas bibliotecas, desenvolvido na segunda metade do século XIX e claramente filiado às correntes positivistas?

Nessa perspectiva, a experiência mais bem sucedida é o projeto ICONCLASSI7 sistema decimal alfanumérico de classificação de temas, objetos e personalidades presentes na arte representacional. O sistema decimal possui uma estrutura que pretende atender a qualquer material iconográfico, além de permitir arrolar referlncias bibliográficas e fontes associadas ao documento. A estrutura é similar ao sistema biblioteconômico. A partir de nove categorias, capazes de conter tudo que é passivel de ser descrito iconograficamente, há subdivisões que aprofundam a descrição introduzindo e articulando demais elementos (personagens, situações, objetos).

O sistema encontra-se organizado tendo como referência a arte ocidental da antigüidade aos nossos dias. Projetos envolvendo esté sistema têm sido mais freqüentes em institutos e museus de arte ${ }^{18}$ não em arquivos, bibliotecas ou instituições que detém principalmente imagens fotográficas. Sua estratégia de classificação baseia-se nos niveis de descrição iconográfica formulados por Panofsky e tem como principal escopo a associação com as referências bibliográficas sobre o mesmo tema descrito.

Outros sistemas como os Thesauri for Graphic Materials, aplicado na Library of Congress (Washington/EUA) ou o Art and Architecture Thesaurusis pretendem também fornecer uma estandardização na an.lise de conte dos visuais a partir de vocabulários que reúnem categorias de termos descritivos e temáticos I"ofness" ou seja, a descrição dos elementos morfológicos imediatamente identificáveis da imagem e "aboutness", o tema ou assunto a que se refere). Mais apropriado para fotografias, o Graphic Materials recebeu contribuições que o ampliaram, abordando também técnicas e processos fotográficos, além de aplicações mais específicas, voltadas para temas e assuntos referenciados pela classificação biblioteconômica (Betz, 1986, 1988).

Entre a universalidade proposta pelo ICONCLASS e a generalização dos vocabulários desenvolvidos no âmbito de coleções formadas no interior de bibliotecas, há ainda uma terceira vertente que não descarta a possibilidade de formulação de vocabulários específicos criados em total consonância com a coleção que se pretende classificar (cf. Sunderland, 1982). Esses vocabulários podem conter termos de uso mais geral com a adição, dependendo da coleção, de termos específicos.

No Brasil, as experiências nesse campo parecem se enquadrar melhor nesta última possibilidade. As grandes coleções fotográficas, ao contrário do que ocorreu na Europa, Estados Unidos e principalmente Canadá, só nos últimos 20 anos passaram a receber um tratamento específico, e mesmo assim com dificuldades na ałualização de equipamentos e programas.

Atualmente, entre os profissionais ałuantes na área de documentação de acervos fotográficos brasileiros esboça-se uma tentativa de mobilização para
17. Concebido pelo historiador da arte holandes Henri van de Waal na década de 40 , sua primeira versão foi o DIAL, Index para arte dos paises baixos (1951). Descle então, as diversas versões do ICONCLASS foram ampliadas graças às experiências de aplicação nos mais diversos acervos das artes plásticas. Já nesta década, projetos utilizando 0 sistema espalham-se por diversas instituiçoes de países da Furopa. Não temos notícia : da aplicação deste sistema no Brasil ou em outro país da América Latina

18. Sobre o tema ver número especial da Visual Resources (1991, v. VIH., n.1) dedicado ao uso deste sistema em diversas instituiçıes de arte.

19. $O$ Ait and Architecture Thesaurus foi elaborado em fins da década de 1970 atendendo às necessidades de informatização dos procedimentos de catalogação e indexação das bibliotecas de arte e arquitetura. Sobre o tema, ver Visual Resources, 1994, v, X, n. 3. 
20. O Thesamns para Acertos Museologicos (Helena Dodd Ferrez e Maria Helena S. Bian chini, editado pelo SPHAN/Minc, 1987) tem como alvo os acer vos de objetos e somente classifica a fotografia na classe Comunicaçào, subclasse Documento. Esta sub-clas se, que reúne documentos textuais, cartográficos e iconográfi cos, foi aberta, segundo as autoras, para os casos de museus que náo possuem arquivos ou bibliotecas (Cf, V.2 p.231). A fotografia (processo positivo direto) é referenciada, neste caso, apenas quanto ao seu suporte material (ambrótipo, daguerreótipo, ferrótipo). Temo identificadores do conteúdo iconográfico constam somente na classe Artes Visuas/Cinematografia, sub-classes Desenho. Escultura e Pintura.

21. No que se refere ao acervo fotográfico, ele é significativo por contemplar as principais tecnicas e formatos utilizados na virada do século. Reúne peças dos mais importantes fotó grafos que atuaram em Sáo paulo no mesmo perìodo (Militão Augusto de Azevedo, Guilher me Gaensly, Valério Vieira, Carneiro e Gaspar, Henschel, entre outros). Do ponto de vista temático, predominarn os registros urbanos, com ênfase na cidade de são Paulo,e os retratos de familia Soma-se a isso, importante coleçao de discussões em torno de sistemas de descrição imagética, mas não existem, para museus e instituições afins, propostas concretas de estandardização de sistema documental para imagens visuais, a exemplo do Thesaurus para Acervos Museológicos 20 .

No caso da catalogação informatizada das coleçães iconográficas do Museu Paulista, nossa proposta não ambicionou postular um vocabulário genérico com aplicação indiscriminada a todo e qualquer suporte iconográfico. Muito pelo contrário, nossa experilncia tem sido no sentido de desenvolver para as coleções especializadas vocabulários descritivos dirigidos tendo como horizonte norteador as linhas de pesquisa que se utilizam de acervos iconográficos e seus temas mais recorrentes, como a história do corpo, da gestualidade e a sua representação pictórica e fotográfica no retrato.

Nesse sentido, mais uma vez a abordagem técnica encontra-se a serviço da pesquisa. Interessa-nos, sobretudo, explicitar para o pesquisador, alvo de um museu universitário, as potencialidades das coleções para a produção do conhecimento histórico. O acervo iconográfico reunido no Serviço de Documentação Textual e lconografia abrange uma considerável diversidade de suportes _ de materiais impressos a daguerreótipos; passando por pinturas a óleo, desenhos, aquarelas, plantas e mapas, além das fotografias, seu acervo mais numeroso. ${ }^{21}$ Seria inconceblvel pretender um vocabulário único para tal variedade tipológica à qual corresponde também uma variedade temática. Assim, até o momento, e é nesse âmbito que discorremos, desenvolvemos um vocabulário controlado voltado para fotogratia e, mais especificamente, para os dois gêneros mais populares desde sua invenção _ a paisagem $e o$ retrato.

Optamos por trabalhar unicamente com as palavras-chave (sobre o tema, no Brasil, ver Smit, 1987), abolindo a descrição textual da imagem. Evitamos, assim, abordagens com alto grau de subjetividade, mesmo aquela possivel de recuperação através de sistemas de hipertexto (indexação para remissão automatizada a partir de um determinado número de repetições da palavra em texios livres, narrativos).

O preenchimento deste campo de descritores respeita normas de padronização para a descrição sintética da imagem e conta com um vocabulário controlado com base no qual será constituído o "menu" que estará à disposição do pesquisador no terminal de consulta (ver Anexo III. Os descritores _ como o próprio nome indica _ devem se ater exclusivamente aos elementos constantes na imagem, sem caráter analítico. Com essa perspectiva, definiu-se o nível de descrição do conteúdo que, longe de ser exaustivo, indica apenas aqueles elementos de identificação imediata. Tivemos sempre em mente que a referenciação não deve pretender substituir a imagem, mas sim orientar e facilitar o acesso a ela.

Como a ficha catalográfica, experiências anteriores haviam permitido a formação de vocabulários controlados de peças fotográficas do acervo 22 (ver Anexo IV). Para a elaboração do vocabulário relativo às fotografias urbanas, foram utilizados o Thesaurus de Arquitetura da fau/usp e a listagem de termos do Banco de Imagens-Módulo Fotografia do Itaú Instituto Cultural, além de incluir os termos específicos como logradouros e localidades (para uma versão aplicada em pesquisa ver Carvalho \& Lima, 1997). Para os retratos, a referência principal 
foi o Thesaurus lconographique (Garnier 1984)23, especificamente no que se refere às posições e gestos corporais.

As categorias não específicas contêm opções para todas as imagens e por isso o uso de um de seus termos é obrigatório. ... o caso, por exemplo, do gênero, (paisagem ou retrato) ou do tipo de vista (vista interna/estúdio fotográfico ou vista external.

Até o momento, a listagem conta com mais de 500 termos específicos, aglutinados em categorias gerais e subcategorias. São 29 categorias gerais das quais apenas uma conta com subcategoria _ a vista interna-estúdio, maneira pela qual foi possivel isolar tipos de enquadramento, ângulos de vista do corpo, apetrechos e poses realizadas no ateliê do fotógrafo e não fruto de instantâneos já praticados por amadores em casa ou em espaços públicos. Estes termos permitem conhecer e elencar os suporte materiais mobilizados pelo retratista de estúdio, abrindo possibilidades de abordagem dos retratos do ponto de vista da elaboração cênica e suas relações com a construção da identidade pretendida pelo fotografado. Nossa tentativa foi, portanto, no sentido de preencher as lacunas deixadas pela ausência de estudos sistemáticos sobre esses aspectos, fornecendo subsídios para análises que transcendam os atributos mais genéricos relativos à representação da figura humana no retrato fotográfico.

Pela sua extensão e particularidade, os termos específicos que contemplam os tipos de laços de parentesco ou de amizade _ utilizados somente quando, através de depoimentos do doador do acervo ou inscrições na própria foto, isso é possível de ser determinado _ são especificados no campo histórico e indicado no campo descritores genericamente como grupo familiar.

Além dos descritores do conteúdo da imagem, são também controlados os termos relativos à técnica fotográfica empregada e ao estado geral de conservação do documento. Para fins didáticos, no vocabulário em anexo encontram-se listados tão somente os termos aplicados às coleções Militão e Luiz Gonzaga, porém, o uso deste vocabulário estende-se aos demais retratos fotográficos e paisagens que integram o nosso acervo (ver Anexo II). Guardadas as especificidades pertinentes ao suporte, este vocabulário é também aplicado, com modificaçōes mínimas, ao acervo de retratos e paisagens pictóricos.

Tal como encontra-se formatado, espera-se que este vocabulário cresça alimentado por pesquisas que permitam, por exemplo, cobrir a falta de termos apropriados para a descrição da indumentária de época, incluindo tipos de cabelos, barbas, bigodes e costeletas, bem como equipamentos presentes na paisagem urbana.

\section{A conservação e restauração}

tratamento físico das duas coleções foi feito inteiramente nos laboratórios do Museu Paulista ${ }^{24}$ e orientou-se pela intervenção mínima nos materiais originais e, por fim, pela ação preventiva. $\bigcirc$ tratamento abrangeu higienização, restauração dos documentos e confecção de embalagens.

A higienização foi feita, no caso das ampliações fotográficas, com trincha e pó de borracha, técnica que não utiliza produtos químicos e remove resíduos de pó e gordura superficiais. A desinfestação com fungicida foi aplicada cartōes postais referentes a Sào Paulo, Sántos e demais cidades do país. Na pinacoteca sào de indiscutivel valor as coleçoes de pinturas,desenhos, aquarelas e gravuras de artistas como Rodolfo e Henrique Bernardelli, $\mathrm{M}$ iguelzinho Dutra, Wasth Rodrigues, Benedito Calixto, Almeiclá Jr., Pedro Américo, Rugendas, etc. Há de se ressaltarem ainda os clesenhos arquitetónicos do engenheiro Tommaso Gaudenzio Bezzi, responsävel pelo projeto do edifício do Musen Paulista (1883). Do matcrial iconografico impresso, destacamse os cartazes e demais dispositivos publicitá rios relativos a movimentos políticos brasileiros (periodos Império, Republicano, Revoluça de 32 ). No tocante às colecões de plantas e mapas, predominam aquelas referentes à cidade e alo Estado de são Paulo.

22. O Banco de Dados lconográficos - Projeto financiado pelo $\mathrm{CNPq}$ (1991-95), reúne documentaça iconográfica impressá e fotográfica, produzida entre fins do século XIX e meados deste século e foi $o$ piloto para o desenvolvimento da ficha catalografica do Museu Paulista e clo vocabulários específicos e pertinentes ao seu acervo. A partir desse piloto pudemos testar e avaliar a eficiência da ficha $e$ dos mecanismos de busca do programa desenvolvido especialmente para este fim. 
23. O Thesaumis Iconograpbique começou a ser elaborado em 1976 , para atender parte das necessidades do Inventaire Général des Monuments et des Ricbesses Artistiques de la France e da Direction des Musées de France. Em 1983, na época de sua publicação, o thesaurus havia sido utilizado em 41.937 pinturas, desenhos e esculturas de diferentes museus, entre eles, 0 Museu do Louvre, Museu de Cluny, Museu do Jeu de Paume, Museu Rodin, entre muitos outros.

24. Yara Petrella (coordenadora), Marcos Antônio Steiner, José Camilo dos Santos, Sônia Spigolon e Anna Luisa Sarti (estagiária). O projeto teve assessoria do Centro de Conservaça e Preservação Fotográfica -Funarte/IBAC

25. O remendo consiste na fixaçào de cortes no papel através da aplicação de tiras de papel neutro de fibras longas.

26. A reintegração é a reconstituiçào da parte faltante do documento com papel neutro de fibras longas.

27. A desacidificação é a lavagem do documento em papel com. água alcalinizada, que resulta na mudança do $\mathrm{pH}$ cido do papel, responsăvel pela sua deterioração, para um $\mathrm{pH}$ próximo ao neutro.

28. A velafura é uma técnica utilizada para aumentar a sustentaçào do documento e que somente nos documentos textuais envolvendo o uso de uma câmara de fumigação que esteriliza o documento ao mesmo tempo que retira o resíduo tóxico deixado pelo produto químico.

Com exceção dos negativos, a maioria das fotografias encontra-se colada sobre suporte de papel, na forma de livros, álbuns, cartões e passepartout. Devido à ação do tempo e ao manuseio freqüente, estes suportes sofreram ressecamento, que resultou em cortes, rachaduras e perdas de partes, especialmente nas bordas do documento. Por isso, nestes casos, a restauração abrangeu a aplicação de remendos 25 , reintegrações ${ }^{26}$, desacidificações (nos casos exclusivamente em papel| ${ }^{27}$ e velaturas ${ }^{28}$. Da emulsão folográfica foram retiradas mecanicamente (com bisturi) particulas de sujeira, resíduos de colas e fita adesiva e as reas com falta de emulsão sofreram retoques a lápis. As duzentas e seis ampliações avulsas foram tratadas segundo o quadro abaixo:

\begin{tabular}{|l|l|}
\hline tipo de tratamento & Número de ampliações totográficas \\
\hline limpeza mecânica & 206 \\
\hline remoção de sujidade aderida na emulsão & 111 \\
\hline Planificação & 78 \\
\hline Remendo & 63 \\
\hline Obłuração & 13 \\
\hline Retoques & 03 \\
\hline
\end{tabular}

No caso dos documentos encadernados, a restauração consistiu na desmontagem da encadernação, da qual foram removidos resíduos de cola e pregos, substituídos por costuras e colas reversíveis de $\mathrm{pH}$ neutro. Após a desmontagem foi feita a hidratação do couro com o objetivo de recuperar um pouco da flexibilidade original. Novas lombadas foram acopladas às originais e as carcelas 30 foram refeitas. As partes faltantes nas capas de couro, percalina e papel foram enxertadas com material similar e as falhas de pigmentação foram preenchidas com retoques de anilina (courol ou de aquarela (papell). As guardas ${ }^{31}$ originais foram revestidas com papel de $\mathrm{pH}$ neutro para a proteção do miolo. Apenas no caso de um dos livros de controle, que reúne fotografias no formato carte-de-visite coladas, optou-se pela desmontagem da encadernação e a sua manutenção em folhas avulsas acondicionadas em caixa confeccionada sob medida, sem a perda da ordenação original. A reencadernação resultaria na duplicação da altura de uma lombada considerada já crítica para o tipo de material.

A última etapa do tratamento consistiu na embalagem. Todos os volumes foram acondicionados em caixas de papelão duro, revestidas com folhas de papel com $\mathrm{pH}$ neutro. Cada unidade fotográfica avulsa recebeu uma embalagem individual _ jaquetas de poliéster com sustentador de papel. $\bigcirc$ poliéster é uma opção interessante pois permite a visão da imagem sem a necessidade de retirá-la da embalagem. Para os negativos em vidro optou-se por envelopes e jaquetas exclusivamente de papel, para maior proteção contra a luz. Este envelope, por sua vez, é guardado em caixa de arquivo de prolipropileno 32 . Com exceção das caixas teitas sob medida para os livros e álbuns, todas as embalagens foram adquiridas prontas. 
A exposição

A exposição e o cd-rom foram escolhidos como os primeiros produtos de difusão cultural das coleções. Assim, não se trata de produtos que fecham o ciclo de pesquisa desta documentação mas, pelo contrário, o inauguram.

A mostra São Paulo nas Lentes de Militão linaugurada em abril/1997) adotou como eixo de discussão as mudanças proporcionadas pelo retrato fotográfico na representação da figura humana. De instrumento de distinção social, peça única criada pelas mãos talentosas do pintor em grandes telas a óleo, o retrato se transforma, a partir da fotografia, em objeto de consumo do grande público. O retrato fotográfico é sintoma e agente de uma época em que a individualidade é valorizada e para a qual são constifuídas categorias genéricas de sujeito. Os procedimentos no estúdio, envolvendo a banalização da postura corporal, dos acessórios de vestuário e da montagem cênica, e, como conseqüência, da fisionomia, embasavam a tarefa de constituir a identidade do cliente.

No projeto museográfico, o conceito da exposição está presente em todos os momentos (ver Anexo V). Nos painéis, a idéia de massificação representa-se pela planta topográfica da cidade à qual estão sobrepostos os retratos de figuras ilustres que deram seus nomes às vias públicas; está presente também nos anúncios da imprensa no painel de artistas atuantes na cidade e fotografados por Militão; ou ainda na listagem de endereços industriais e comerciais retirada dos almanaques de época, semelhantes ao que hoje são nossas páginas amarelas e sobre a qual se sobrepõem os retratos de moradores como o jornaleiro, a engomadeira, o astrônomo, o barbeiro etc.

A reprodutibilidade fotográfica está sugerida no papel de parede que reproduz quase na forma de textura uma das páginas do livro de controle de Militão, repleto de pequenas imagens justapostas, e que preenche os vários nichos da sala. Os padrões de molduras para as imagens fotográficas do século XIX encontram ressonâncias principalmente nas arcadas e reentrâncias do partido arquitetônico de inspiração palaciana do edifício que abriga o Museu Paulista. A associação entre desenho arquitetônico e estética fotográfica ficou valorizada por uma iluminação difusa direcionada para o teto a partir das sancas que destacou a arquitetura da sala. Textos simplificados e em número reduzido bem como a adoção de legendas sumárias deixam que os sentidos presentes na exposição se organizem de forma predominantemente visual, como deve ser em se tratando de fotografias.

Ao mesmo tempo que cabia à exposição apresentar as coleções através de uma amostragem representativa dos retratos, foi necessário dar visibilidade à sua forma de organização em tipologias _o busto masculino, a mulher de corpo inteiro, o casal, a mãe com o filho, o homem com guarda-chuva etc. $\bigcirc$ painel que sintetiza a problemática histórica referente ao retrato consiste em uma grande parede falsa, ao fundo da sala, com aberturas nas quais giram cubos de tamanhos variados, em cujas faces estão coladas reproduções de retratos, que formam grupos tipológicos em tonalidades diferentes que podem ser manipulados pelo visitante através de timões colocados na base do painel. Cada timão controla uma linha de cubos e com eles pode-se formar várias séries de consiste ná aplicação de una folha de papel transparente neutro de fibras longas sobre toda a superficie do documento. Esta técnica foi utilizada em todas as folhas de seda, coloridas e com a marca do ateliê de Militão, utilizadas para entrefolhar os livros de controle $\mathrm{e}$ álbuns fotogrficos.

29. A limpeza mecânica envolve limpeza com pó de borracha, pincel e soprador.

30. As carcelas sào tiras em papel e tecido às quais se fixam as folhas internas de uma encadernaçào.

31. As guardas são folhas que se colocam no comeco e no fim do livro encadernado $\mathrm{e}$ que unem a capa ao volume.

32. Material plástico que não degrada coma a açào do tempo, nào emite gases e protege a documentaçào de umidade. 
retratos muito semelhantes na sua composição. Ressalta-se, nesse caso, o aspecto lúdico e interativo deste painel, importante para um museu que recebe um número significativo de crianças e adolescentes (ver Anexo V).

Na sala contígua à sala principal o visitante pode apreciar um número significativo de originais fotográficos. A presença dos livros de controle, uma câmera fotográfica de época, a cadeira e o enfeite usados por Militão no estúdio, ao lado de um conjunto de retratos que cumpriram o ciclo de consumo (daguerreótipos, retratos em porcelana, cartes-de-visite, cabinet-portraits, molduras etc.) representam a trajetória deste objeto do desejo, que se inicia na sua produção no ateliê e termina nos porta-retratos sobre os móveis da sala de esiar, nos álbuns de familia, nas bolsas e carteiras dos entes queridos, nas lápides dos túmulos etc.

Completa a mostra a apresentação do documentário fotográfico urbano realizado por Militão em 1862, e que constitui um dos registros mais antigos da arquitetura colonial urbana paulista de que se tem notícia. Estas imagens estão apresentadas na sala que comporta a maquete da cidade de São Paulo em 1841, peça de grandes dimensões $(5,5 \times 6,5 \mathrm{~m})$, moldada em gesso pelo escultor Henrique Bakennisł em 1922, por ocasiáo das comemorações do centenário da Independência. As fotografias de Militão fazem parte do quadro de referências para a sua produção. Atração permanente do museu, a maquete apresentava problemas na sinalização dos logradouros e edifícios mais importantes, que foi então resolvida sem a interferência na peça. O ilusionismo, próprio das miniaturizações, e que convive com as intervenções críticas na exposição, foi enriquecido pela produção de um "passeio" por doze pontos da cidade através de um espetáculo de som e luz.

O CD-Rom

O CD-ROM São Paulo nas Lentes de Militão proporciona o acesso a informações sobre as coleções através de opções de navegação que coloca ao alcance do usuário possibilidades de abordagem que variam em grau de abrangência e profundidade. O CD-ROM foi projetado em duas versōes, uma disponível na exposição, mais resumida e compacta $€$ outra destinada à venda, mais completa, que deve atender a adolescentes e adultos interessados no tema e servir como instrumento didático para escolas, ou material de apoio para as visitas ao Museu.

Para o usuário estão disponíveis desde informações institucionais sobre - Museu Paulista-USP e a Fundação Roberto Marinho até dados específicos sobre as coleções Militão e Luiz Gonzaga e sobre o projeto de curadoria, além de textos de apoio sobre a história da fotografia.

As coleções são apresentadas por uma seleção fotográfica significativa de cada tipologia de documentos e textos que relatam a trajetória deste acervo até a sua chegada ao Museu, além de dados biográficos dos fotógrafos e históricos dos ateliês.

Na apresentação do projeto de curadoria são relatados os procedimentos para a catalogação e recuperação física das coleções. 
Entremeados com cenas de vídeo, este segmento apresenta detalhes técnicos poucas vezes divulgados em projetos deste tipo.

Três passeios pela cidade são oferecidos através de uma planta de São Paulo da segunda metade do século XIX. Ao longo do caminho escolhido o usuário encontra as imagens produzidas por Militão do ponto onde se encontra o transeunte virtual, obtém informações sobre a história urbana neste período, e, se for de sua vontade, compara a imagem da época com o mesmo local hoje ${ }^{33}$.

Merece destaque o segmento Fotografando com Militão ${ }^{34}$, que apresenta ao usuário, através de fotografias e desenhos, o interior de um estúdio fotográfico, incluindo desde a sala de visita, passando pela preparação do cenário, até a revelação da imagem no laboratório.

\section{A pesquisa}

No vasto campo da historiografia, os estudos do corpo começam, a partir dos anos 70, a ocupar um espaço significativo no conjunto de uma produção interessada em analisar comportamentos, práticas e representações sociais. "O corpo passa, pois, a interessar ao historiador como espaço constitutivo de laços sociais. Seus atos, gestos e práticas são elementos de uma cultura, retratam sistemas de valores específicos, organizam um modo de vida" (Del Priore, 1995: 14-5). Sem um arcabouço teórico-metodológico específico e sem contar com uma perspectiva unificadora, os trabalhos nesta área são marcados por uma grande diversidade de abordagens e problemáticas relativas ao corpo e suas relações com a vida social. São analisados os ritos de passagem como nascimento, casamento e morte, bem como os modos de relacionamento da sociedade com as doenças, a manutenção e a reprodução biológica, as expressões do amor, da sexualidade, da beleza, as formas de transcendência do corpo material, a gestualidade corporal e sua interação com a dança, a música, - teatro, a festa, a constituição social de categorias como masculino e feminino a partir das representações do corpo, suas relações com a casa, com as máquinas etc. Para compreender este novo objeto, os historiadores analisaram os comportamentos demográficos, debruçaram-se sobre os documentos seriais, como atas de batismo, processos civis e religiosos, expressões materiais dos ex votos, abriram-se para as fontes não tradicionais como indumentárias, imagens e objetos trazidos à luz pelos trabalhos arqueológicos, manuais educativos e de etiqueta, pinturas, brasões, obras normativas e literatura de época (Del Priore, 1995: 9-26) ${ }^{35}$.

Ao colocar o corpo no centro da discussão de fenômenos sociais, a historiografia abriu novos caminhos de reflexão sobre os retratos fotográficos. No Brasil, por um longo tempo, o interesse pela sistematização e análise de fotografias desembocou na produção de repertórios documentais fac-símiles, álbuns, coletâneas de coleçōes particulares e institucionais onde o tema predominante eram as paisagens urbanas. Colada a esta produção de natureza empírica surgem publicações voltadas para o tratamento técnico da imagem fotográfica formas de catalogação, acondicionamento físico, restauração, informatização etc. Uma história da fotografia no Brasil começa a se estabelecer, também nos anos 80, cobrindo os pontos de interesse demarcados pela
33. Este segmento foi elaborado por José Geraldo Simòes Jr. e conta com fotografias atuais de Sergio Mekler.

34. Este segmento foi elaborado por Ricardo Mendes.

35. Para una visào crítica solbre os estudios do corpo ver também os comentários de diferentes especialistas ao texto de Mary Del Priore, publicados na secão Debates da mesma revista (Anais do Musen Paulista. v.3. 1995). 
produção internacional neste campo específico descobertas, expansão espacial e temporal do suporte fotográfico, desenvolvimento tecnológico, temas recorrentes, biografias de estúdios e fotógrafos, formas de produção e consumo etc. No entanto, é nos anos 90 que melhor se define o uso da fotografia como fonte de pesquisa para o entendimento de processos sociais de produção de sentido. Se a cidade tem cadeira cativa também nestes estudos, o enfoque de temas relativos à família através da fotografia assume quantitativamente igual relevância (Cf. Carvalho; Lima ef al. 1994:253-300).

Neste ponto de intersecção entre uma história social do corpo e uma história social da visualidade, o retrato fotográfico situa-se como uma fonte privilegiada. A passagem da produção dos retratos confeccionados artesanalmente por pintores, ou ainda, na primeira fase da fotografia, por daguerreotipistas e pelos chamados "fotógrafos artistas", para aquela de produção dos retratos em formato carte-de-visite, inventado por Disdéri na França de 1854 , e do qual os retratos de Militão são herdeiros, informa sobre as transformações da representação do indivíduo nos primórdios da massificação por que passa a nossa sociedade de consumo. A estereotipagem dos retratados está associada às novas relações que se estabelecem entre a representação do corpo e aquela da fisionomia, à representação do feminino e masculino, da família, da infância valorizada na produção intensa de imagens individuais, inclusive aquelas de cadáveres infantis, ou ainda dos negros representados como brancos em fotografias que convivem num imaginário alimentado pelos registros do escravo como figura exótica, tipo de rua etc.; enfim, um grande catálogo de imagens que traz elementos para a análise das formas de produção de identidades.

Nesta perspectiva, o retrato fotográfico passa a ser percebido pelo historiador como parte do processo de constituição do sujeito social, no qual devem ser considerados não apenas os tipos humanos representados, mas o modo como estes se articulam a um repertório de poses e de objetos organizado dentro do estúdio fotográfico de forma a compor personagens diversos. Assim, foi a partir de questões delineadas pelas pesquisas em curso que se considerou a relevância da coleção de Militão Augusto de Azevedo e a pertinência do desenvolvimento e aplicação de um vocabulário controlado que transcendesse os níveis genéricos de simples acesso à imagem, paro permitir o mapeamento de padrões de poses constituídos através de mais de 12.000 retratos.

encaminhamento de formas de descrição específicas para os retratos destas coleções, o que vem de encontro às linhas de pesquisa praticadas pelos profissionais do Museu Paulista, não significa a exclusão de outros caminhos de exploração científica que os retratos e paisagens da coleção permitem desenvolver. Vale a pena ressaltar, por exemplo, que os estudos de representações urbanas encontram nas fotografias de Militão e em suas múltiplas formas de reedição uma fonte importante para a compreensão da prática social de reconstituição do passado, processo através do qual são criados sentidos de continuidade. A seqüencialidade presente no álbum comparativo, por exemplo, serve como uma baliza cronológica para a marcação das regularidades e rupturas da vida social. Se olharmos para a longa trajetória dos usos sociais destas imagens, veremos como elas têm sido utilizadas como matéria-prima para a produção de sentimentos de tranqüilidade e segurança, e para o exercício das 
funções de legitimação, de integração e construção da memória. Os diferentes sentidos que se constituiram a partir das imagens da cidade de São Paulo produzidas por Militão nos anos de 1862-87, em circuitos tão diferenciados como o político, o científico, o educacional e o cultural, permitem que se analisem as formas de apropriação do documento visual. Exemplos desses usos são os documentários arquitetônicos, repertórios fotográficos, ou fac-símiles publicados sobretudo nos últimos 20 anos.

Também a história da fotografia ganha com informações a respeito da organização da produção no estúdio, das relações com fornecedores, dos equipamentos, dos preços e do comportamento do mercado. Os estudos pioneiros de Boris Kossoy $(1979,1981)$ e mais recentemente de Cândido Grangeiro (1994) trilharam esta vertente. $\bigcirc$ estudo da estética fotográfica, no viés ainda pouco estudado que é o da compreensão das relações das técnicas de coloração com os padrões de gosto da época, tem na coleção Militão um imenso e variado mostruário de nuanças de tonalidades praticadas _ as conhecidas viragens.

Os profissionais da área de restauração e conservação fotográfica encontram nesła coleção exemplares das raras chapas de colódio e um manancial de informações sobre o comportamento do papel albuminado, seus fixadores e sobre o contato da fotografia com diferentes corantes e substâncias adesivas.

As coleções Militão e Luiz Gonzaga são suficientemente ricas para cobrir um amplo espectro de preocupações pertinentes a diferentes áreas do conhecimento que vão desde a história social, passando pela história da arte, arquitetura, urbanização, sociologia, até áreas de natureza técnica ou artística.

\section{Conclusão}

Se a pesquisa deve nortear o conjunto de procedimentos relativos à curadoria de acervos para que seja possível evitar desvios que comprometam o próprio sentido de existência do museu universitário, hoje é preciso que as parcerias com os patrocinadores sigam esta mesma orientação.

Os investimentos em projetos culturais seguem, via de regra, a lógica do mercado ou são atraídos pelas isenções fiscais oferecidas pelo Estado. A política de incentivo associada à necessidade de desenhar e cristalizar uma imagem sólida e segura da empresa patrocinadora transformou a cultura em um bom negócio. A mercantilização do conhecimento parece ser um processo inevitável e em certo grau imprescindivel para a manutenção das atividades de instituições culturais hoje. Entretanto, a expc "ência com o projeto Militão mostranos que é possível e necessário garantir aquelas etapas da curadoria que são fundamentais para a constituição do objeto em documento, mas que não são o alvo por excelência do interesse publicitário.

Por outro lado, naquilo que o museu oferece de visibilidade e que, portanto, tende a catalisar os investimentos do patrocinador como no caso de exposições, catálogos, vídeos, CD-ROMs etc., a liberdade de interferência externa vai até 0 ponto $\mathrm{em}$ que as funções do museu não sejam obliteradas. Nesse sentido é que se justifica a manutenção dos projetos culturais sob a coordenação de uma curadoria institucional. É preciso não esquecer que a 
imagem do patrocinador forma-se sobre uma outra imagem a do museu. E esta última, acredita-se, tem muito mais a ver com responsabilidades sociais do que com necessidades de marketing.

\section{BIBLIOGRAFIA CITADA}

ART and archicteture thesaurus. dir.Tony Peterson. New York: Oxford University Press; Published behalf of the J. Paul Getty Trust. 1990.3 v.

BETZ, Elisabeth W. \& ZINKHAM, H. Descriptive Terms for Graphic Materials:Genre and Physical Characteristic Heading Washington DC: Library of Congress, 1986.

BETZ, Elisabeth W. Grapbics Materials:Rules for Describing Original Items and Historical Collections, Washington DC: Library of Congress, 1982.

BETZ, Elisabeth W. LC Thesaurus for graphics materials. Washington DC: Library of Congress, 1988.

BIANCHINI, Maria Helena S. e FERREZ, Helena Dodd. Thesaurus para Acervos Museológicos. SPHAN/Minc, 1987

BREFE, Ana Cláudia. Um lugar de memória para a Nação. O Museu Paulista reinventado por Afonso d'Escragnole Taunay (1917-1945). Campinas, 1999. Tese (Doutorado), Universidade Estadual de Campinas (ms.).

CARVALHO, Vânia Carneiro de; LIMA, Solange Ferraz de. Folografia e cidade: da razão urbana à lógica do consumo. Álbuns de São Paulo (1887-1954). São Paulo, Mercado de Letras, 1997.

CARVALHO, Vânia Carneiro de; LIMA, Solange Ferraz de; Carvalho, Maria Cristina Rabelo de; RODRIGUES, Tânia Francisco. Fotografia e história: ensaio bibliográfico. Anais do Museu Paulista. São Paulo. n. ser. v.2 p.253-300 jan./dèz. 1994.

DELOCHE, Bernard. Museologica: contradictions et logique du musée. Savigny-le-Temple: éditions W. MNES, 1989.

DEL PRIORE, Mary Lucy Murray. Dossiê: a história do corpo. Anais do Museu Paulista. São Paulo. n.ser. v.3.p.9-26 jan./dez. 1995.

DOOLEY. Jackie M. Processing and Cataloging of Archival Photograph Collection. Visual Resources, vol. XI, 1995. pp 85-101.

FERREZ, Helena Dodd, BIANCHINI, Maria Helena S. Thesaurus para acervos museológicos. Rio de Janeiro: Fundação Nacional Pró-Memória. Coordenadoria Geral de Acervos Museológicos, 1987.

FÜRST, Hans Jörg. Material Culture research and the curation process. In: PEARCE, Susan M (ed.). Museum Studies in Material Culture. London;New York: Leicester University Press, 1989, p. $97-110$. 
GARNIER, François. Thesaurus iconographique. Système descriptif des représentations. Paris: Ministère de la Culture/ Le Léopard D'Or, 1984.

GATHERCOLE, Peter. The fetishism of artefacts. In: PEARCE, Susan M (ed.). Museum Studies in Material Culture. London/New York: Leicester University Press, 1989, p.73-81.

GRANGEIRO, Cândido Domingues. as artes de um negócio: a febre photographica. São Paulo 1862-1886. Campinas, 1993.266p. Dissertação (Mestrado), Universidade Estadual de Campinas.

KAVANAGH, Gaynor. History curatorship. Leicester; London: Leicester University Press, 1990.

KOSSOY, Boris. Militão Augusto de Azevedo e a documentação fotográfica de São Paulo (18621887): recuperação da cena paulistana através da fotografia. São Paulo, 1978. 121 p. Dissertação (Mestrado) - Faculdade Escola de Sociologia e Política de São Paulo.

LAURITO, Ilka Brunhilde. Retratos de um photographo. In: SÃO PAULO. São Paulo em três tempos: álbum comparativo da cidade de São Paulo (1862-1887-1914). São Paulo: IMESP, 1982.

LEMOS, Carlos.Metamorfose paulistana. In: SÃO PAULO. São Paulo em três témpos: álbum comparativo da cidade de São Paulo (1862-1887-1914). São Paulo: IMESP, 1982.

MENDES, Ricardo. Literatura Técnica (1840-1940): Enciclopédias, manuais, periódicos. São Paulo: Centro Cultural São Paulo/SMC-Prefeitura Municipal, 1991/1992. (ms).

MENESES, Ulpiano T. Bezerra de. Do teatro da memória ao laboratório da História: a exposição museológica e o conhecimento histórico. Anais do Museu Paulista. História e Cultura Material. São Paulo: Museu Paulista, nova série, n.2, v.2, p. 9-42, jan./dez. 1994.

MENESES, Ulpiano T. Bezerra de. Plano Diretor do Museu Paulista da USP São Paulo, Museu Paulista, 1990. (ms)

SILVA, Cássia Maria Mello da (coord.). Manual para catalogação de documentos fotográficos (versão preliminar). Rio de Janeiro: Funarte/IBAC, Fundação Bibliteca Nacional, IBPC/Museu Histórico Nacional, IBPC/Museu Imperial, FGV/Centro de Pesquisa e Documentação de História Contemporânea do Brasil da Fundação Getúlio Vargas, 1992. (ms).

SMTT, Johanna. Análise da imagem: um primeiro plano. In: SMIT, Johanna V. (org.). Análise documentária: análise da sintese. Brasília, MCT/CNPq/ IBICT, 1987, p. 99-111.

SUNDERLAND, John. Image collection: librarians, users and their needs. Art Libraries Journal (summer, 1982. p. 41-49).

TOLEDO, Benedito L.; KOSSOY, Boris. São Paulo:álbum comparativo da Cidade de São Paulo. 18621887. São Paulo: s.e., 1981.

TURNER, James M. Subject Access to pictures: Considerations in the surrogation and Indexing of Visual Documents for Storage and Retrievel. Visual Resources, vol. IX, 1993. pp 241-271. 


\section{ANEXO I - Telas do catálogo informatizado}
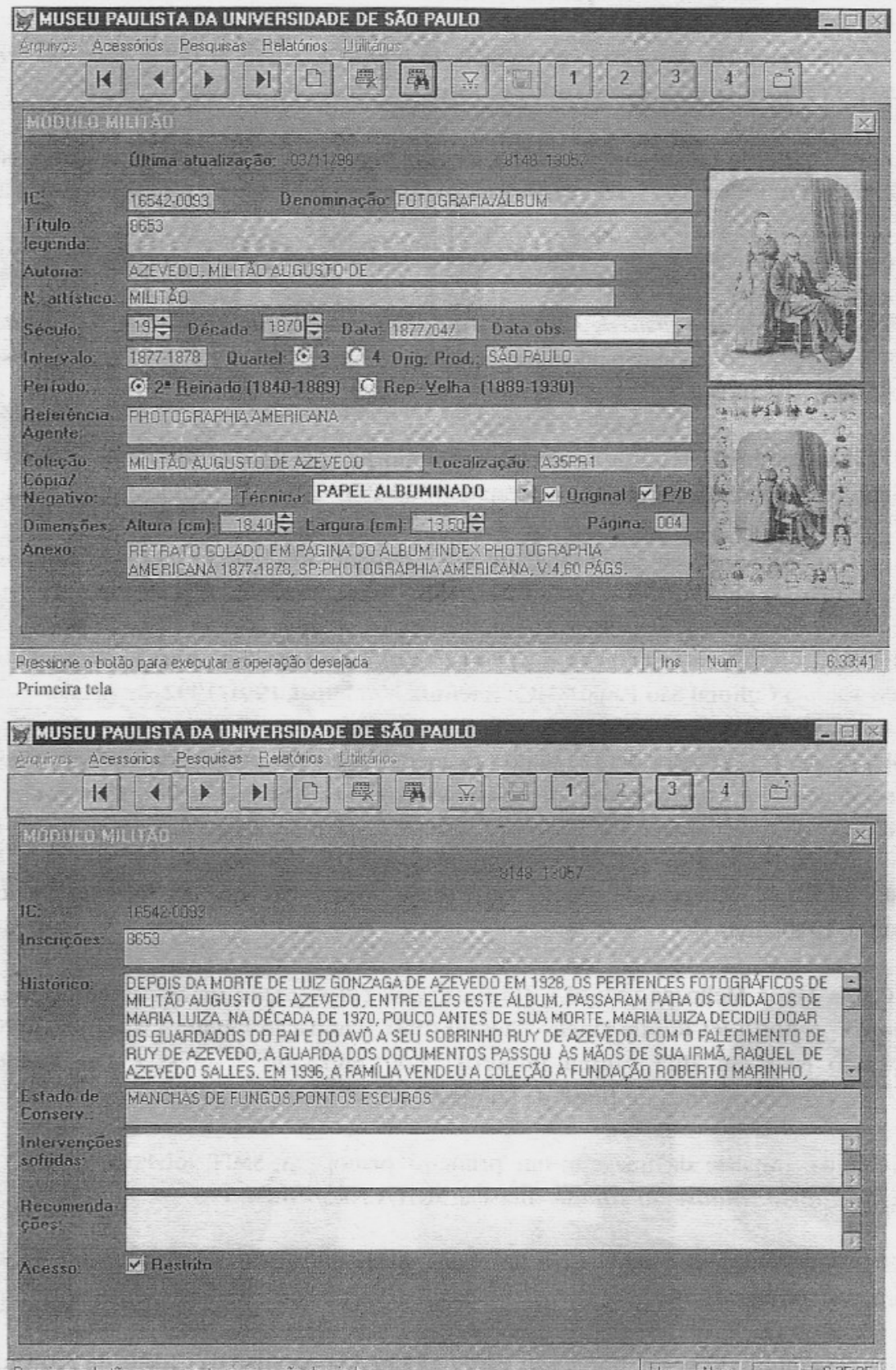

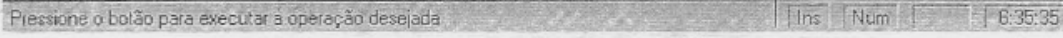

Segunda tela 


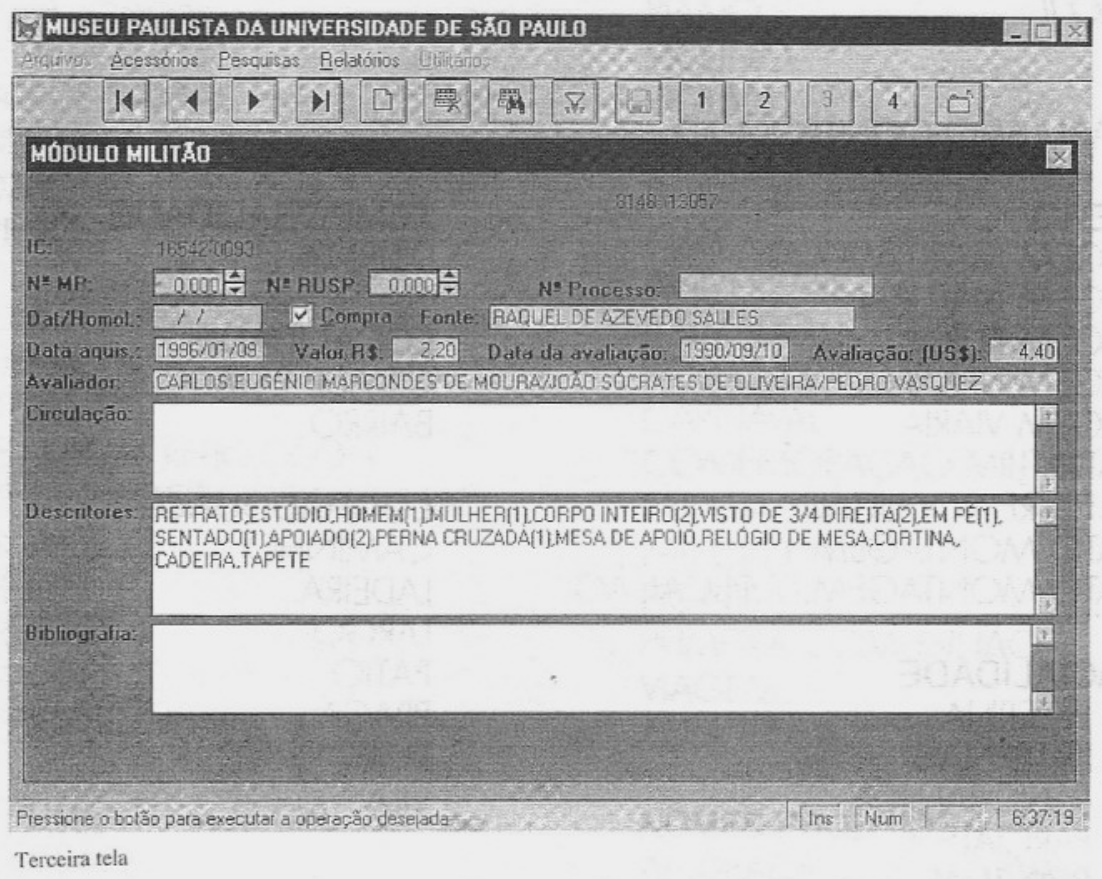

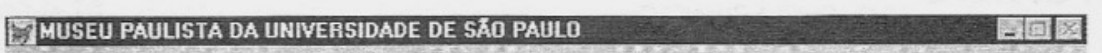

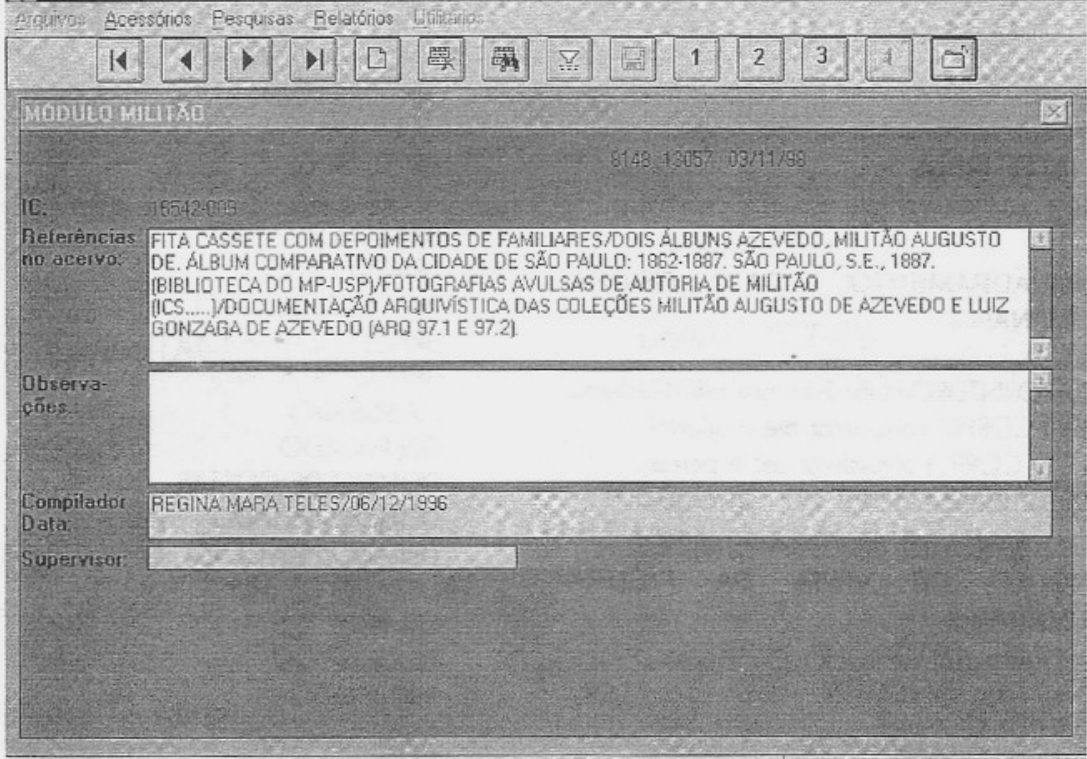

Pressione o bolão para execular a operaçăo desejada $\quad$ _

Quarta-tela 
VOCABULÁRIO CONTROLADO

GÊNERO

PAISAGEM MARITIMA

PAISAGEM NATURAL

PAISAGEM RURAL

PAISAGEM URBANA

PAISAGEM VIÁRIA

RETRATO

RETRATO REPRODUCÃO

RETRATO MONTAGEM

RETRATO MONTAGEM:DUPLICAÇÃO

\section{ESPACIALIDADE}

VISTA EXTERNA

VISTA INTERNA

VISTA PANORÂMICA

VISTA PARCIAL

VISTA PONTUAL

\section{TEMPORALIDADE}

DIURNA

LOCALIDADE

CIDADE:ESTADO

BAIRRO

LOGRADOURO

CAMINHO

LADEIRA

LARGO

PÁTIO

PRACA

RUA

VILA

\section{VISTA INTERNA}

ESTÚDIO

ENQUADRAMENTO DA FIGURA
HUMANAInO)
BUSTO
CORPO INTEIRO considerar dos pés à cabeça
MEIO CORPO considerar até o quadril
$3 / 4$ DO CORPO considerar até a perna
ROSTO

ÂNGULO DE VISTA DA FIGURA
HUMANA|nO)
VISTO DE - DIREITA
VISTO DE ESQUERDA
VISTO DE COSTAS
VISTO DE FRENTE
VISTO DE PERFII
VISTO DO ALTO
POSTURA (nO)
ABAIXADO
ABRACADO
AGACHADO

AJOELHADO

APOIADO

BRACO CRUZADO

BRACO DADO

BRACO ESTENDIDO

BRACOO FLEXIONADO

BRACO PARA TRÁS

CABISBAIXO

DEBRUCADO

DEITADO DE COSTAS

DEITADO DE LADO

DEITADO NO COLO

DEITADO DE BRUCOS

EM PÉ

ENCOSTADO

INCLINADO

MÃO CRUZADA

MÃO DADA

MÁO NA BOCA

MÃO NA CINTURA

MÃO NO PEITO

PERNA ABERTA

PERNA CRUZADA

PERNA FLEXIONADA

PORTANDO 
SENTADO NO COLO

SENTADO

MOBILIÁRIO

BALCÄO

BUFFET

CADEIRA

CADEIRA COM BRACO

CADEIRA DE BALANCO

CADEIRĀO

CAIXÄO lobjeto funeráriol

CANASTRA

CRISTALEIRA

ESCABELO (banquinho para pôr os pés)

ESPELHO

GENUFLEXÓRIO

MESA

MESA DE APOIO ( $p$ / mesa pequenal

PAINEL-CENÁRIO

POLTRONA

POLTRONA SEM BRACO

SOFA

\section{ACESSÓRIOS CENÁRIO}

ABAJOUR

AGUIHA DE CROCHÊ

AIMOFADA

ALTAR

AMPULHETA

ÂNFORA

ARMA DE FOGO

ARRANIO FLORAL

ÁRVORE GENEALÓGICA

BALAUSTRADA

BASTÄO

BENGALA

BIBELOOO

BÓIA

BOLSA

BROXA

CACHIMBO

CADERNO

CAIXA DE COSTURA

CAIXA DE PINTURA

CANETA.PENA

CANTLL

CAPACETE

CARTA DE BARALHO

CASTICAL

CAVALETE

CERCA

CESTA

CESTA COM FLORES

CHAPÉU

CHARUTO

CHICOTE
CIGARRO

COLUNA

COPO

COPO COM BEBIDA

CORTINA

CRUCIFIXO

DOCUMENTO

ENFEITE DE MESA

ESCULTURA

ESPADA

ESQUADRO

ESTATUETA

FACA

FAIXA

FLOR

FIORES

FRUTEIRA

GAIOLA

GAMELA

GARRAFA

GARRAFA DE BEBIDA

GUARDACHUVA

JORNAL

LÁPIS

LENCO

LEQUE

LIVRO

LOUCA

LUSTRE

LUVA

MALETA

MANTA lchecar se não é

indumentária)

MÁQUINA DE SORTEIO

MÁQUINA FOTOGRÁFICA

MEIA-COLUNA

MORINGA

MURETA

OBJETO lquando não for possivel identificar)

ÓCULOS

PÁ

PALHETA

PAPEL

PARTITURA

PATINS

PEDRA-CENÁRIO

PELE DE ANIMAL

PENA

PINCEL

PLANTA

PRATO

PRESÉPIO

PRUMO

QUADRO

RÉGUA

RELÓGIO
36 Usado para qualquer enfeite sobre o móvel 
RELÓGIO DE MESA

ROLETA DE JOGO

SACA-ROLHA

SEGURADOR DE POSTURA

SERROTE

SINETE

SOMBRINHA

TACCA

TAPETE
TECIDO

TELA

TINTEIRO

TOALHA DE MESA

TRONCO DE ÁRVORE

VASO

VASO COM FLORES

VASO COM TAMPA

\section{VISTA INTERNA (cont.)}

SALA DE JANTAR

SALA DE ESTAR

SALA DE MÚSICA

COZINHA

ALPENDRE

LAREIRA

\section{ACIDENTE GEOGRÁFICO/VEGETAÇÃO}

VEGETACÃO

ARBORIZAÇÃO

CAVERNA

GRUTA

BAÍA

ILHA

MAR

MATA ATLÂNTICA

MORRO

PRAIA

RIO

SERRA DO MAR

VÁRZEA

COMUNICAÇÕES

CANAL MARITIMO

ESTAÇÃO FERROVIÁRIA

PONTE

PORTO

TECIDO URBANO

TRILHO DE BONDE

VIA FÉRREA

VIADUTO
INFRA-ESTRUTURA URBANA/RURAL

CALCCAMENTO

CERCA

CERCADO

CONSTRUCÃO

DEMOLICÃO

ILUMINACC̃O

ILUMINAĊ̃̃O A GÁS

ILUMINAÇÃO ELÉTRICA

MAQUINÁRIO

OBRAS

PAVIMENTAÇÃO

PIANTACCÃO

CAIXA D'ÁGUA (checar se é doméstica)

EQUIPAMENTO FERROVIÁRIO

PARA-RAIO (checar se é doméstica)

SINALEIRO

EDIFICAÇÕES/USOS/FUNÇÕES

ARMAZÉM

BANCO

CAPELA

CEMITÉRIO

CONFEITARIA

EDIFICAÇÃO COMERCIAL

EDIFICAC̄ÃO PÚBLICA

EDIFICAÇÃO RELIGIOSA

EDIFICAC̄ÃO RURAL

EDIFICAC̄ÃO SOBRADO

EDIFICAÇÃO TÉRREA

ESCOLA

FARMÁCIA

FAROL

FAZENDA 
FORTE

GALPÃO

GARAGEM

HOSPEDARIA

HOSPITAL

HOTEL

IGREJA

INSTITUTO

LIVRARIA

LOJA

LOTÉRICA

MERCADO PÚBLICO

OFICINA

PANIFICADORA

PAPELARIA

RELOJOARIA

RESIDÊNCIA

RESTAURANTE

SAPATARIA

SEMINÁRIO

TEATRO

MIRANTE
REDAÇÃO DE JORNAL

JARDIM PRIVADO

JARDIM PÚBLICO

LAGO

LENHA

MONUMENTO

MURO

PLANTACÃO

PORTEIRA

PORTÃO

POSTE

QUIOSQUE

RELÓGIO

TIJOLO

TÚMULO

FARDO

TELHADO

ATERRADO

ARQUITETURA/SERVIÇOS

DOMÉSTICOS

GALINHEIRO

ESTUFA

QUINTAL

ALPENDRE

PAISAGISMO/MOBILIÁRIO URBANO

TORRE

ANÚNCIO

ARBORIZACCÃO URBANA

BANCO

BANHEIRO PÚBLICO

BARRIL

CABO DE ACOO

FIAC̄ÃO

CHAFARIZ

CHAMINÉ

COQUEIRO

CORETO

CRUZ

ENTULHO

ESPELHO D' ÁGUA

ESTÁTUA

FONTE

GRADIL

AUTOMÓVEL

BARCO A REMO

BARCO A VAPOR

BARCO A VELA

BONDE ELÉTRICO

BONDE TRAÇÃO ANIMAL

CANOA

CARRO DE BOI

TRANSPORTE ANIMAL

TRANSPORTE MANUAL

NAVIO

TREM

CHARRETE

VAGÃO

BICICLETA
37. As relaçōes de parentesco vêm discriminadas no histórico de cada fotografia

38. Quando nāo foi possivel especificar laços de parentesco e houver mistura de gêneros e faixas etárias.

39. Quando nào foi possivel especificar.

0 Para os casos de fantasias.

41. Para os casos de farda

42. Para os trajes religiosos onde não se identifica o ritual

\section{ELEMENTOS MÓVEIS/TRANSPORTES}


SEXO/FAIXA ETÁRIA (n)

BEBÊ

CRIANCCA

HOMEM

IDOSO

IDOSA

MENINA

MENINO

MULHER

MULHER GRÁVIDA

\section{GRUPOS}

GRUPO FAMILIAR37

GRUPO DE PESSOAS38

GRUPO DE ADULTOS

GRUPO DE ALUNOS

GRUPO DE ALUNOS

PROFESSORES

GRUPO DE AMIGOS

GRUPO DE CRIANCAS

GRUPO DE HOMENS

RAÇA

NEGRA
BARBEIRO

BEDEL

CASEIRO

CLÉRIGO

COMERCIANTE

COZINHEIRO

DELEGADO FISCAL

EMPRESÁRIO

ENGENHEIRO

ENGOMADEIRA

ENGRAXATE

FOTÓGRAFO

FUNCIONÁRIO PÚBLICO

JARDINEIRO

MÉDICO

MILTAR

NATURALISTA

E POLITICO

PROFESSOR

PROFESSOR DE MÚSICA:CANTO

PROFESSOR DE MÚSICA:PIANO

TABELLĨO

TRABALHADOR

TRANSEUNTE

TROPA

\section{CONDIÇÃO FÍSICAIESTADO DE VI- ANIMAIS \\ DA \\ ANÃO \\ $\mathrm{BO}$ \\ CADÁVER \\ CACHORRO \\ CARNEIRO \\ ANOMALIA FÍSICA \\ CAVALO \\ GALINHA \\ GATO \\ PERSONAGENS/PROFISSÃO \\ PAPAGAIO}

ALFAIATE

AMBULANTE

ARTISTA 39

BRINQUEDOS

ATOR/ATRIZ

BAILARINA

ANIMAL DE PELÚCIA

BAMBOLE

BICICLETA

CANTOR/CANTORA LÍRICA

BOLINHAS DE GUDE

MÚSICO

PINTOR

BONECA

POETA

CARRINHO DE BONECA

ASTRÔNOMO

CHARRETE 
CORDA

CORNETA

JOGO DE DAMAS

RAQUETE DE TENNIS

RODA

TRICICIO

\section{INDUMENTÁRIA}

FIGURINO4O

UNIFORME 4 II

TRAJE RITUAL RELIGIOSO 42

TRAJE DE PRIMEIRA COMUNHÃO

BATINA

HÁBITO

MORTALHA

TOGA

VESTIDO NUPCIAL

INSTRUMENTO MUSICAL

ACORDEÃO

CLARINETA

PANDEIRO

ANEXO $I I$

PROJETO MILITÃO *

Curadoria

Solange Ferraz de Lima

Vânia Carneiro de Carvalho

Pesquisa e Documentação

Cláudia Moi

Regina Mara Teles

Renata Barbosa Garbellini

Juliana Firmo dos Santos estagiária

Montserrat Moreno estagiária
PIANO

VIOLINO

VIOLÃO

RITOS E EVENTOS

ALMOCO

ANIVERSÁRIO

BATIZADO

BODAS DE PRATA

CARNAVAL

COMEMORACÃ̃O MILTTAR

PARADA MILITAR

FALECIMENTO

PIC-NIC

PRIMEIRA COMUNHÃO

VIAGEM

AULA

\section{NOMES PRÓPRIOS}

ANDRADA E SIIVA JOSÉ

BONIFÁCIO DEI

Maquete de São Paulo

Miyoko Makino

Aureli Alves Alcântara

bolsista/CNPq

Lara Borriero Milani bolsista/CNPa

Suporte de Informática

Luciano Antônio Beraldo

Conservação e Restauração

Yara Petrella coordenação

Jerônimo Dantas Barbosa

José Camilo dos Santos

Marcos Antônio Steiner

Sônia Maria Spigolon

Wlademir Mário Herdina
* Patrocínio da

Fundaçáo Roberto

Marinho e Rede Globo.

A coorclenaça do pro-

jeto na Fundaça

Roberto Marinho ficou

sob a responsabilidade

de Sílvia Finguerut. 
Anna Luisa Sarti estagiária

Assessoria

Centro de Conservação e Preservação

Fotográfica/Funarte

Exposição

Coordenação de Projeto e Produção

Arte 3

Projeto Museográfico

Ana Helena Curti

Claudia Warrak designer gráfica

Fábio Montenegro

Fernando Rodrigues arquiteto

Supervisão de Montagem

Atelier Damiranda

Fernando Rodrigues

Montagem

Cristina Lunardi

lara Machado

Miguel Paladino

Paschoal Moiso

Roberval Layus

Rogério Canela

Yancamill Kulock

Cenotécnica

Felipe Tassara

Leonardo C. de Oliveira

Maurízio Zelada

Assistentes de Produção

Cláudia Polito

Eloá Civolani
Fotografia

José Rosael

Rômulo Fialdini maquete

Sérgio Burgi

lluminação

Somlux

Sonorização

Tunica pesquisa, criação, mixagem e edição

Aline Meyer mixagem e edição

Paulo lvo locução

Casa do Ouvidor, Estúdio Tesis gravação

Comunicação Visual

Insign

Bureau Gráfico

Pigmentum

Serigrafia

Claudio Ramallo

Molduras e Passepartouts

Moldulak

Folder/Design Gráfico

Inventum Design e Soluções

Gráficas

Multimídia

Produção

ATR Multimedia

Textos

Glória Kalil 
José Geraldo Simões Júnior José Sebastião Witter Ricardo Mendes

Sérgio Burgi

Solange Ferraz de Lima

Vânia Carneiro de Carvalho
Fotografia José Rosael Sérgio Burgi

Sérgio Mekler 
ANEXO IV - Imagens e descritores das coleções Militão e Luiz Gonzaga

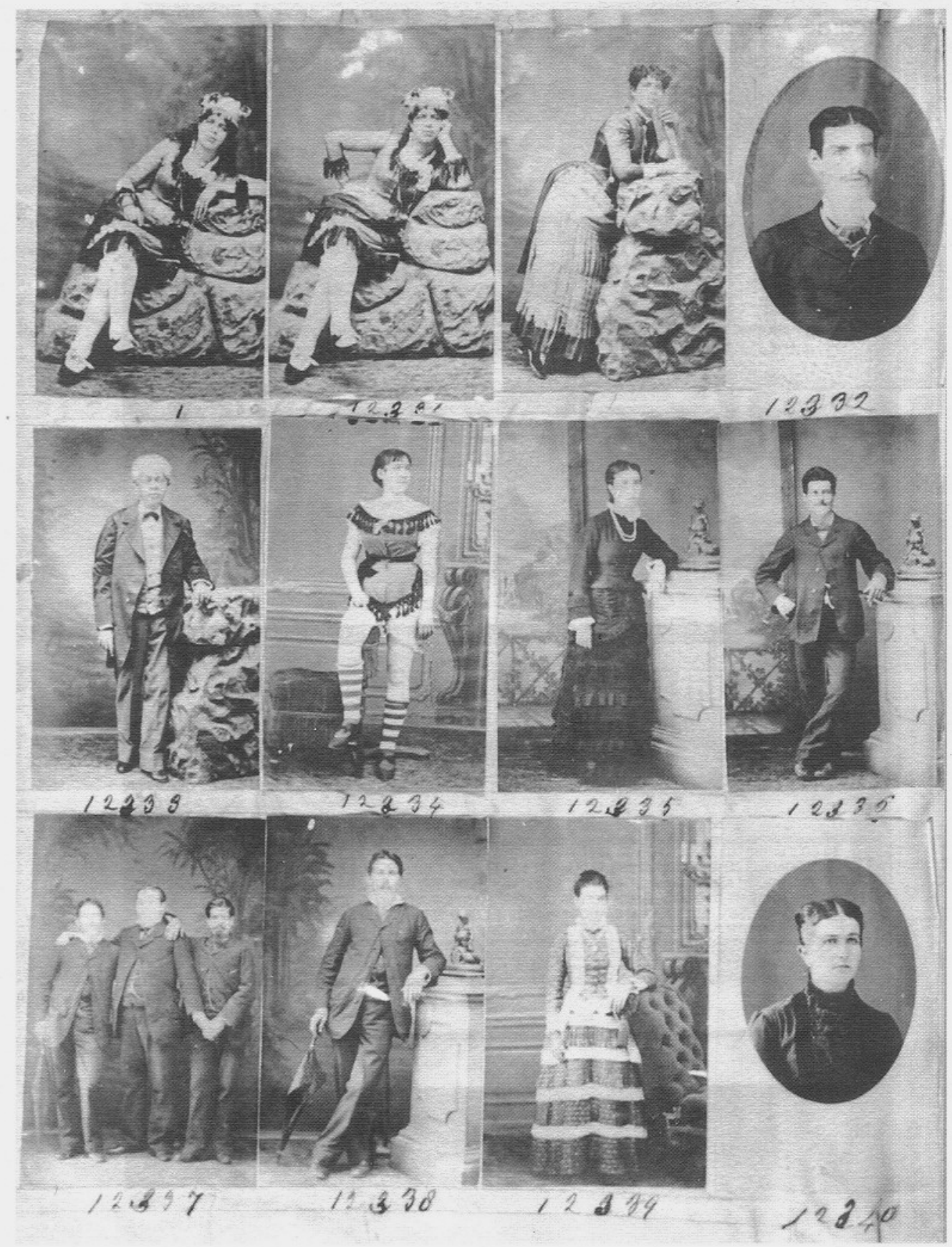

Livro de controle, 1879-1885 (v.6, p.257)

Coleção Militão Augusto de Azevedo Acervo Museu Paulista-USP

Reprodução Sérgio Burgi / José Rosael 
Casal (anônimo)

década de 1880

Coleção Militão Augusto de Azevedo

Acervo Museu Paulista-USP (IC 16544-1579)

Reprodução Sérgio Burgi / José Rosael

Descritores:

retrato, estúdio, homem (1), mulher(1), corpo inteiro(1),

corpo inteiro(2); visto de _ direita(1), visto de esquerda(1), em pé(1), sentado(1), apoiado(2), perna cruzada(1), mesa de apoio, painel-cenário, poltrona sem braço, tapete
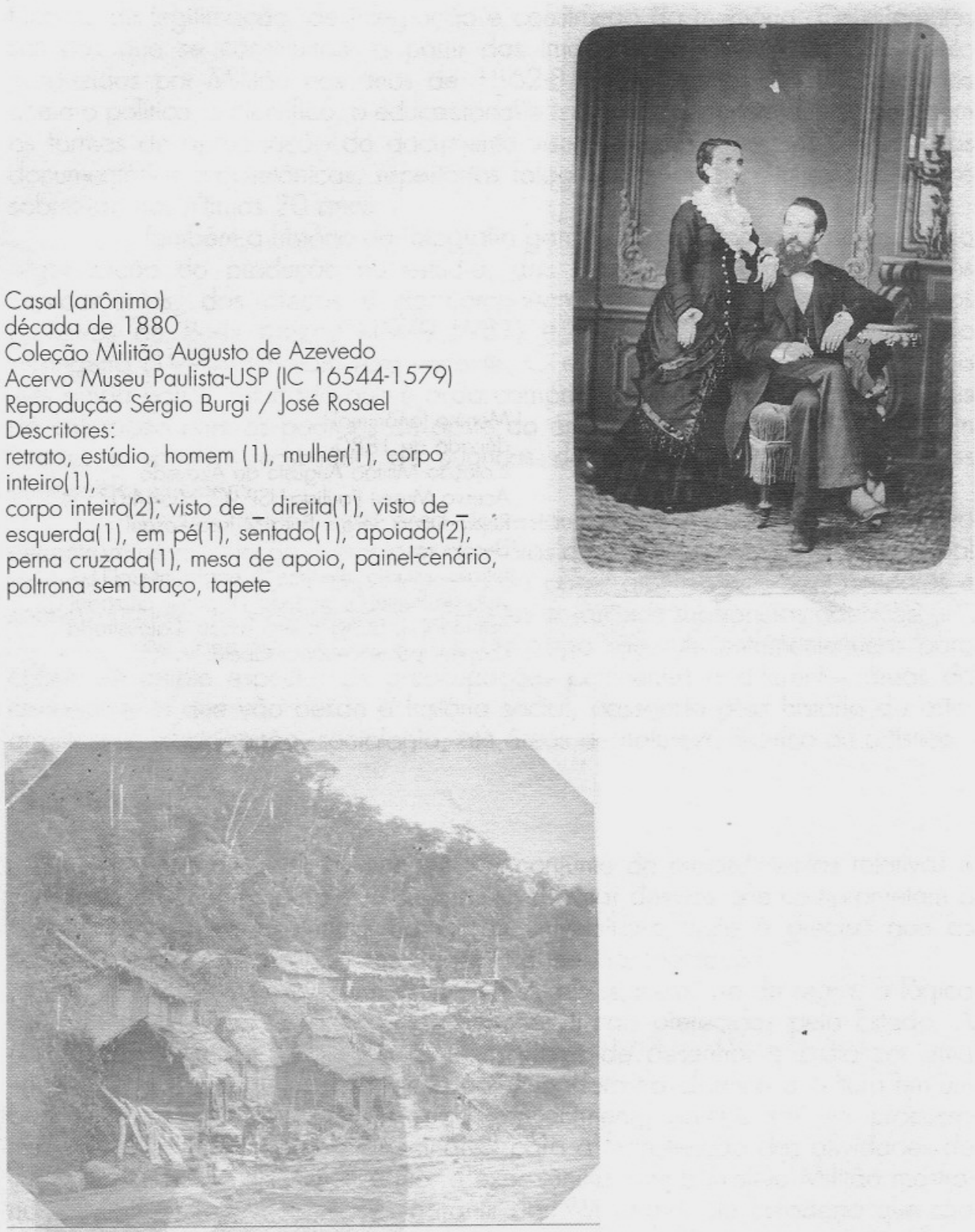

Aldeamento de trabalhadores da São PauloRailway (ferrovia Santos-Jundiai) década de 1860

Coleção Militão Augusto de Azevedo

Acervo Museu Paulista-USP (IC 16729

Reprodução Sérgio Burgi / José Rosael

Descritores:

paisagem viária, vista parcial, diurna, serra do mar:sp, vegetação, mata atlântica, obras,

railway, via férrea, edificação térrea, edificação sobrado, cerca, equipamento ferroviário, trabalhador, homem(4) 


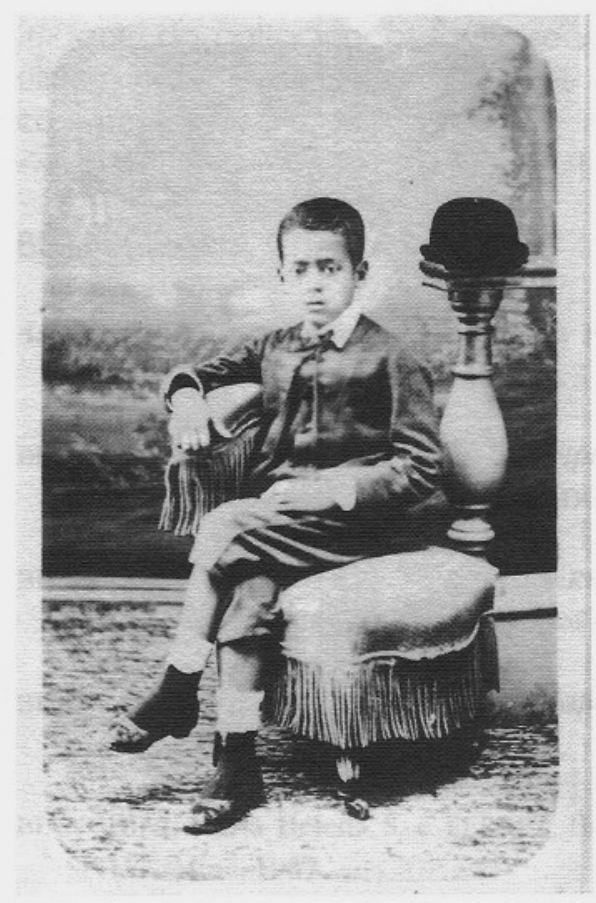

Menino (anônimo)

década de 1880

Coleção Militão Augusto de Azevedo Acervo Museu Paulista-USP (IC 16544-0715) Reprodução Sérgio Burgi / José Rosael Descritores:

retrato, estúdio, ménino(1), corpo inteiro(1), visto de frente(1), sentado(1), perna cruzada(1), apoiado(1), poltrona sem braço, balaustrada, chapéu, painel-cenário, tapete.
Homem (anônimo) década de 1880

Coleção Militão Augusto de Azevedo Acervo Museu Paulista-USP (IC 16544-1602) Reprodução Sérgio Burgi / José Rosael Descritores:

retrato, estúdio, homem(1), busto(1), visto de frente(1)

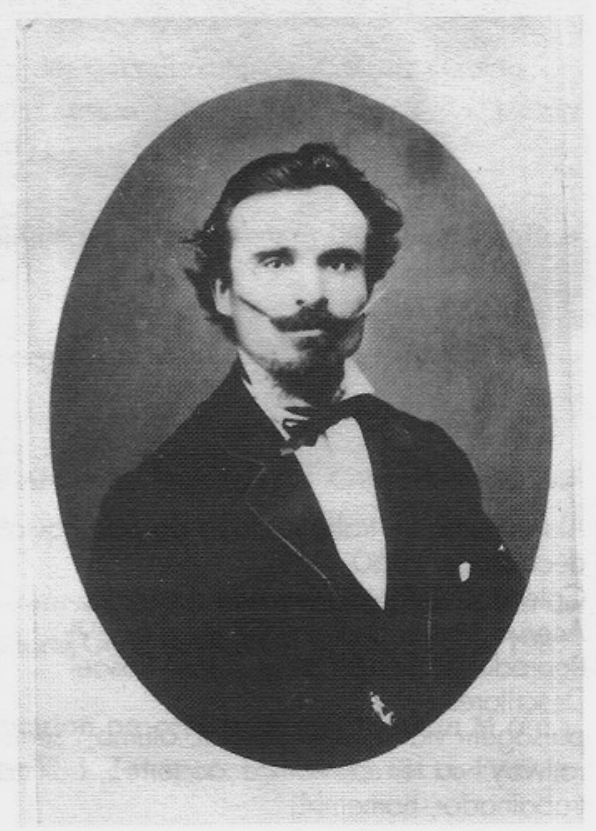




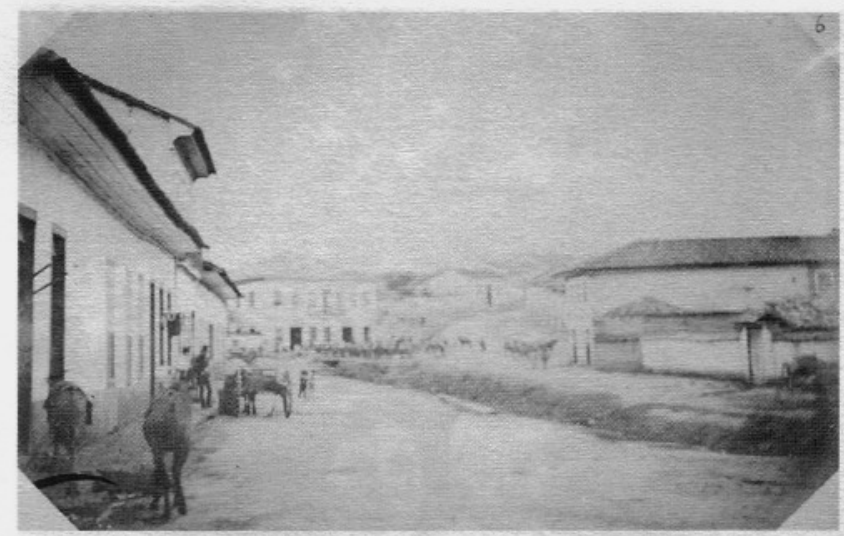

Largo do Riachuelo (atualmente, parte da praça da Bandeira) 1862

Coleção Militão Augusto de Azevedo

Acervo Museu Paulista-USP (IC 16550.0004)

Reprodução Sérgio Burgi / José Rosael

Descritores:

paisagem urbana, vista parcial, diurna, largo do riachuelo, são paulo:sp, edificaçã́o sobrado, edificação térrea, edificação comercial, córrego, transporte animal, cavalo, tropa, homem(2), menino(2)Maria da Glória Cruz de Azevedo,

esposa de Luiz Gonzaga de Azevedo, com Luiz Gonzaga de Azevedo Júnior

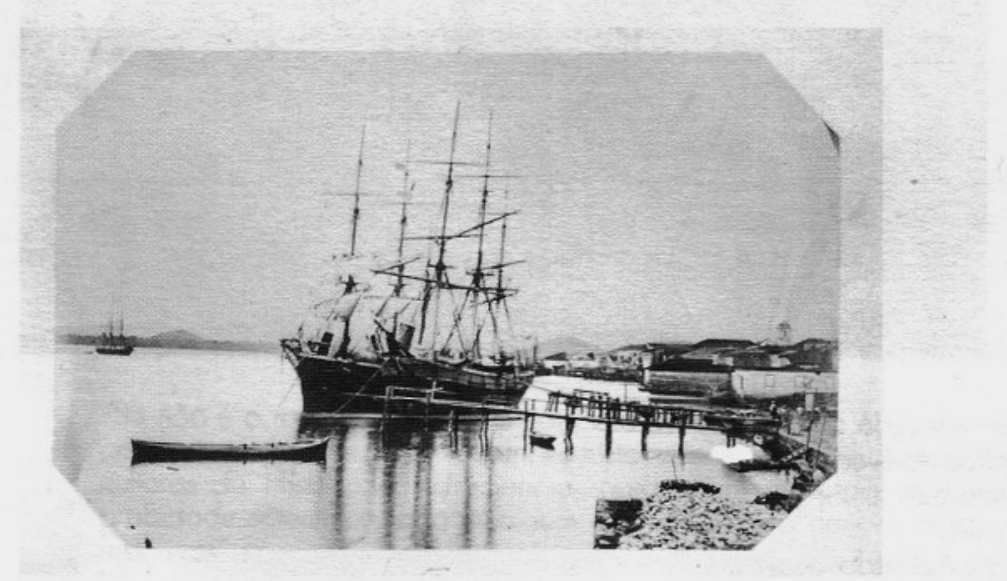

Porto de Santos

década de 1860

Coleção Militão Augusto de Azevedo

Acervo Museu Paulista-USP (IC 16551-0009)

Reprodução Sérgio Burgi / José Rosael

Descritores:

paisagem marítima, vista parcial, diurna, santos:sp, porto de santos, mar, barco a vela, tecido urbano, vegetação 


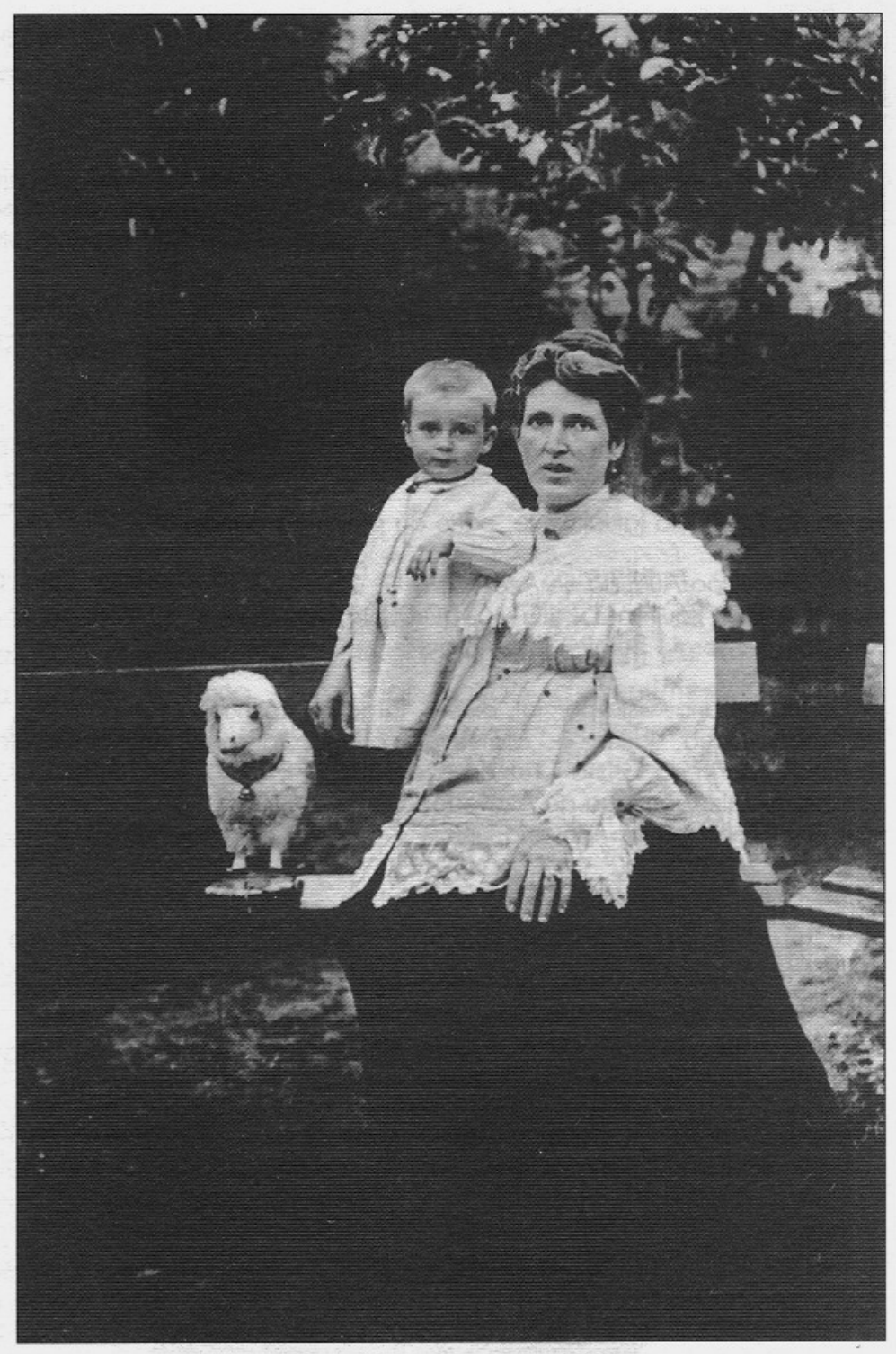

Maria da Glória Cruz de Azevedo, esposa de Luiz Gonzaga de Azevedo, com Luiz Gonzaga de Azevedo Júnior Imagem de álbum da família Coleção Luiz Gonzaga de Azevedo Acervo Museu Paulista-USP (IC 16548.0011)

Reprodução Sérgio Burgi / José Rosael

Descritores:

retrato, menino(1), mulher grávida(1), corpo inteiro(2), visto de 3/4 esquerda(2), em pé(1), sentado(1), braço flexionado(1), abraçado(1), banco, brinquedo:animal de pelúcia, mãe e filho, azevedo junior (luiz gonzaga de)(n. 1), azevedo (maria da glória cruz de)(n.2), paisagem urbana, vista externa, diurna, edificação térrea, residência, jardim, arborização 
* Autoria de Fernando Rodrigues segundo projeto museográfico de Ana Helena Curti, Cláudia Warrak (designer gráfica), Fábio Montenegro e o próprio Fernando Rodri-

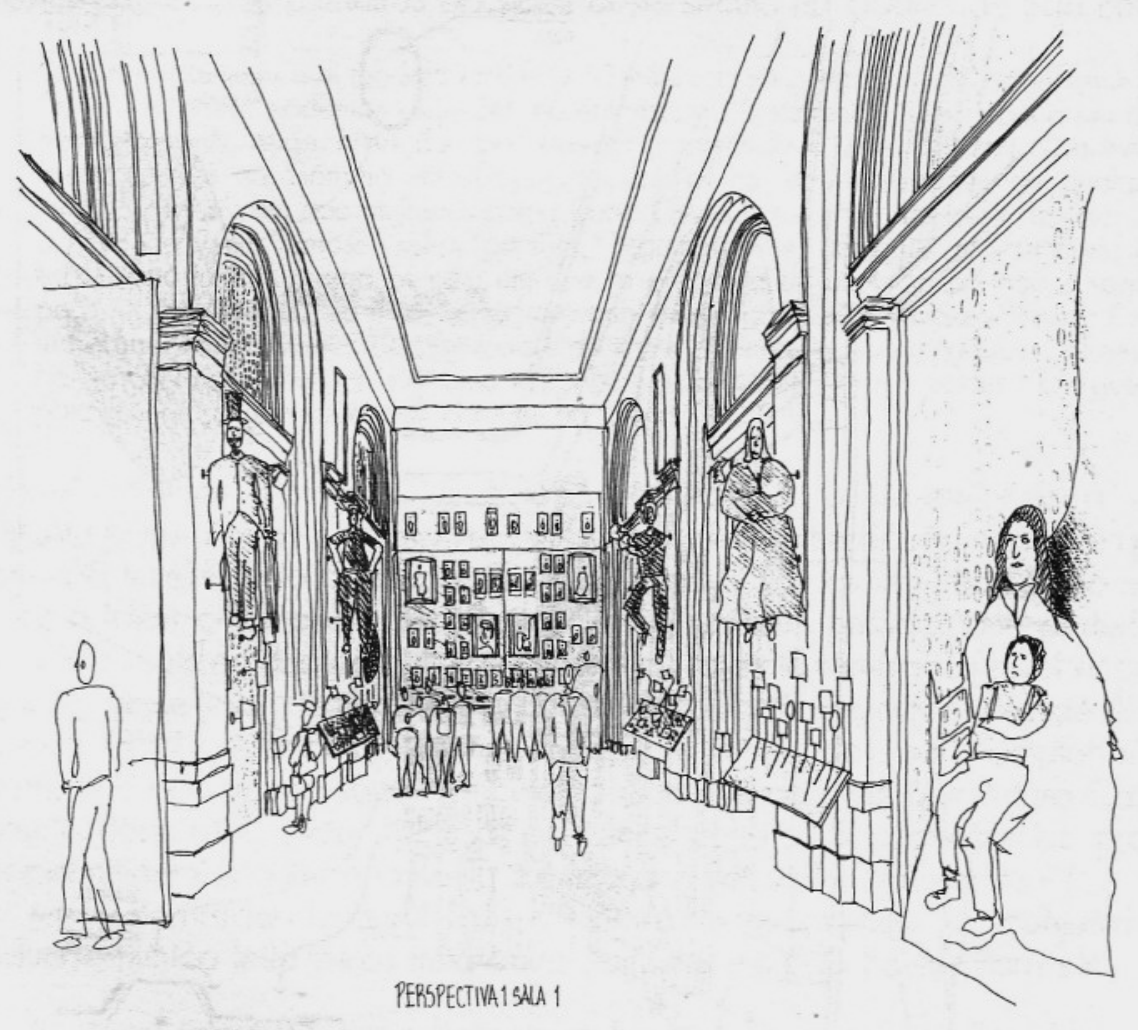
gues (arquiteto). 


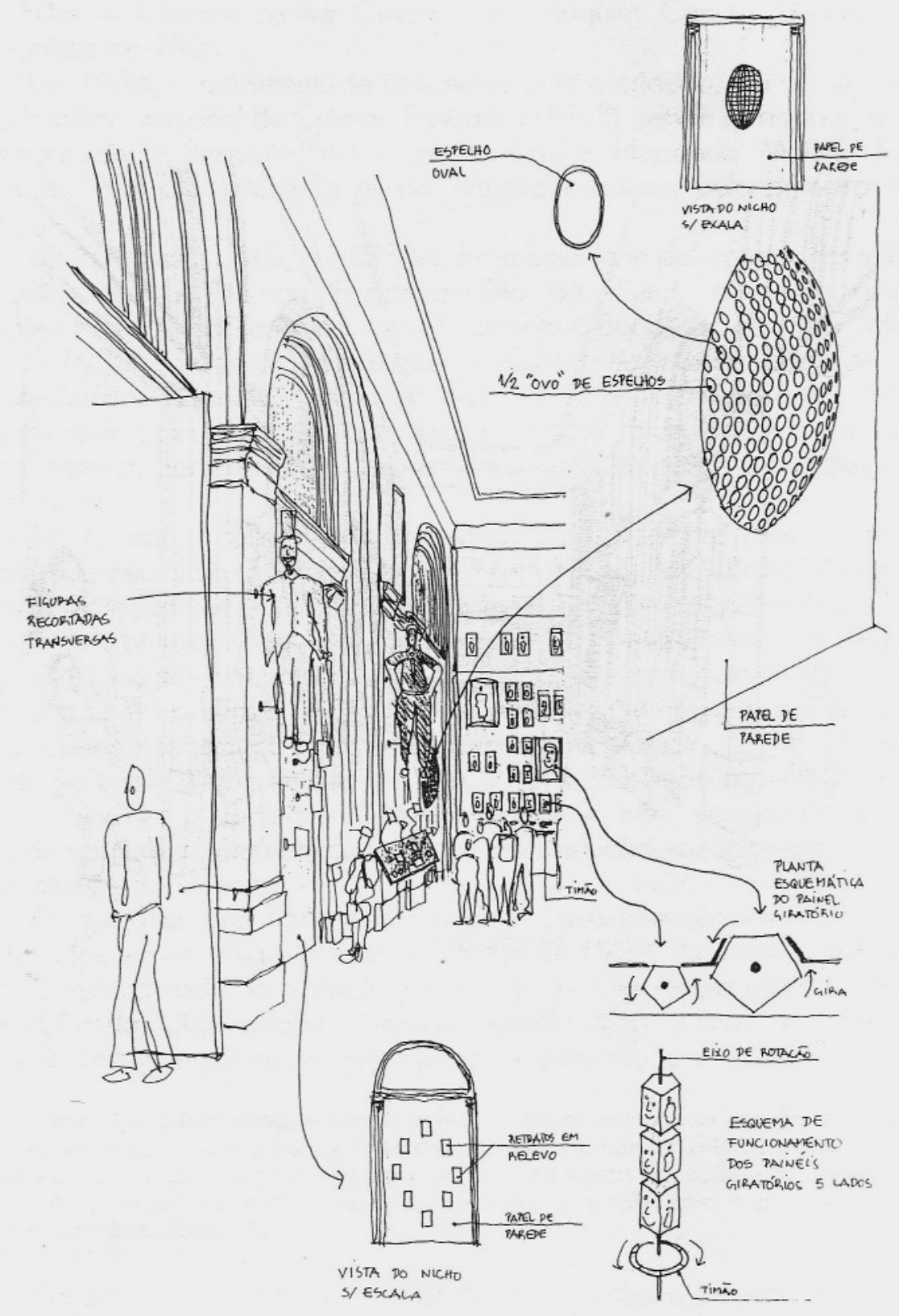




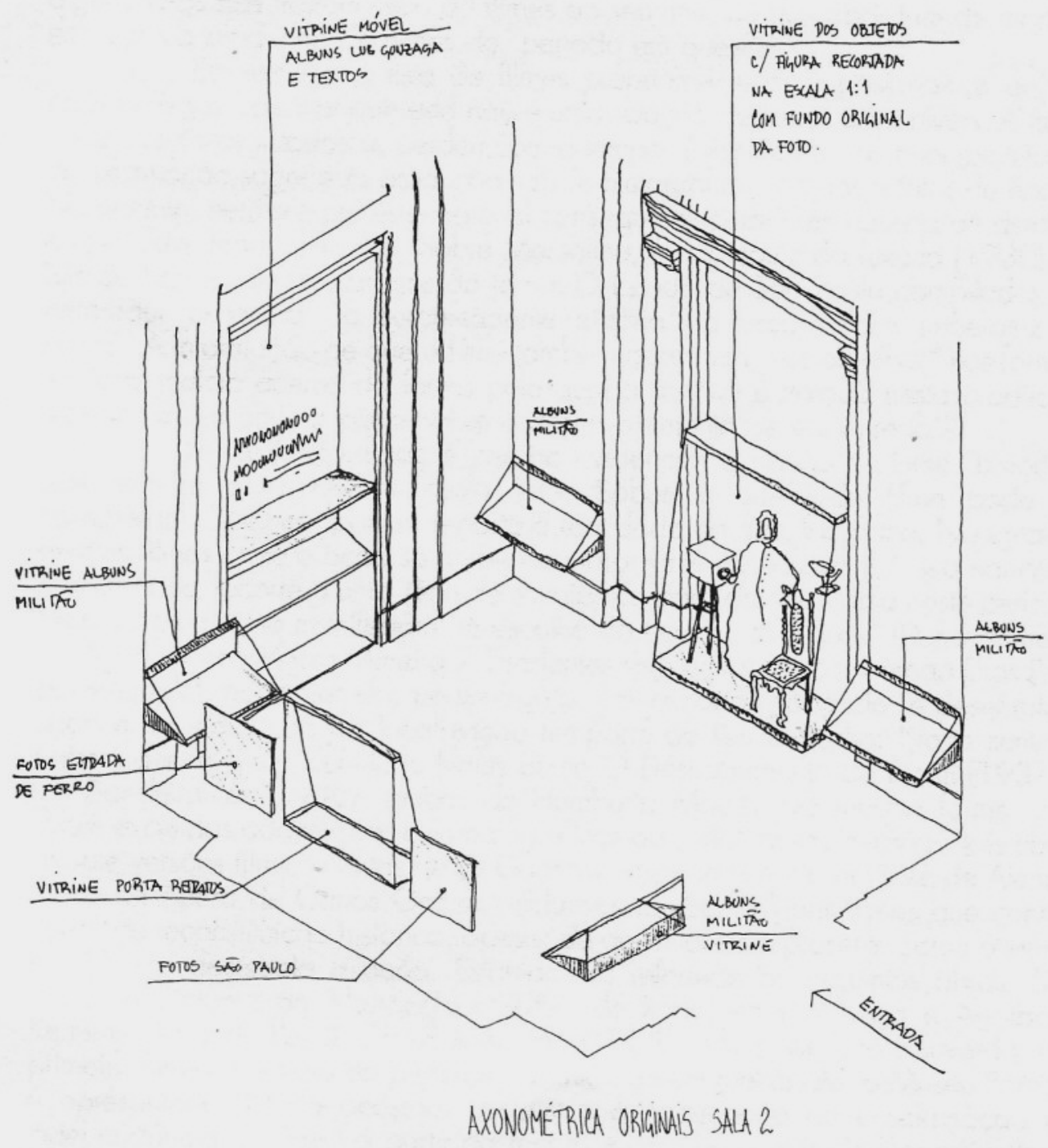


Fotografia no Museu - o projeto de curadoria da coleção Militão Augusto de Azevedo

Vânia Carneiro de Carvalho Solange Ferraz de Lima

O objetivo do presente texio é apresentar a coleção fotográfica de Militão Augusto de Azevedo pertencente ao Museu Paulista da Universidade de São Paulo e discutir os procedimentos documentais adotados para o seu tratamento. São analisados aspectos metodológicos de modo a evidenciar um conceito específico de curadoria, no qual as tarefas de documentação, conservação física e exploraçāo educativa e cultural são orientadas pela pesquisa.

UNTTERMOS: Museu histórico. Fotografia: São Paulo, século XIX

Photography at the Museum - the curatorial project of Militão Augusto de Azevedo's photography collection

Vânia Carneiro de Carvalho Solange Ferraz de Lima

This paper aims at discussing the curatorial proceedings followed in the physical conservation and cataloguing of Militão Augusto de Azevedo's photographic collection (acquired in 1996 by the Museu Paulista da Universidade de São Paulol. Some aspects of the methodological approach are analysed in order to highlight a specific concept of curatorship, in which documentation, conservation and educational tasks are guided by research.

UNTERMS: Historical Museum, Photograph: São Paulo, $19^{\text {th }}$ Century

A representação da história no cinema brasileiro (primeira metade do século)

Eduardo Victorio Morettin

A. levantou três tipos de filmes cinematográficos no Brasil, referentes à história nacional, do começo do século ao fim do Estado Novo: filmes apresentando figuras e eventos históricos, também incluindo temas religiosos (1906-1944), adaptaçōes literárias (1910-1931) e filmes de objetivos patrióticos e militares (1917-1930). Como prefácio à sua lista, ele discute os atributos genéricos do cinema histórico no Brasil, como um gênero, além dos objelivos dos filmes educacionais do período.

UNITERMOS: Cinema histórico: Brasil, 1a. metade do séc.XX.

Historical representation in the Brazilian cinema (first half of the XXth.century)

Eduardo Victorio Morettin

The A. has recorded three sorts of movie pictures in Brazil related to national history, from the beginning of the century until the end of the Estado Novo in the forties: movie pictures featuring hislorical characters and events, also including religious subjects (1906-1944), adaptations from literature (1910-1931) and patriotic-militaristic movies (1917-1930). As a preface to the list he discusses the general attributes of the Brazilian historical cinema as a category, as well as the purposes of the 'educational movie pictures' of the period. 